\title{
LHPP suppresses colorectal cancer cell migration and invasion in vitro and in vivo by inhibiting Smad3 phosphorylation in the
} TGF- $\beta$ pathway

\author{
Bin Hou $\mathbb{D}^{1,4}$, Wenhan $\mathrm{Li}^{2,4}$, Peng Xia ${ }^{3}$, Fengyu Zhao ${ }^{3}$, Zhao $\mathrm{Liu}^{3}$, Qingnuo Zeng ${ }^{3}$, Shilong Wang ${ }^{3}$ and Dongmin Chang ${ }^{3 凶}$
}

(c) The Author(s) 2021

The roles of phospholysine phosphohistidine inorganic pyrophosphate phosphatase (LHPP) in tumorigenesis have been recently proven in hepatocellular carcinoma (HCC), cervical, pancreatic, bladder, and thyroid cancers. Previous research demonstrated that LHPP repressed cell proliferation and growth by inactivating the phosphatidylinositol 3-kinase/AKT signaling pathway in vitro and in vivo. However, the functions and potential mechanisms of LHPP as a tumor suppressor in colorectal cancer (CRC) metastasis are still unknown. Consequently, the Transwell assay and xenograft nude model showed that LHPP inhibited migration and invasion of CRC cells in vitro and in vivo, respectively. The expression of total and nuclear epithelial-to-mesenchymal transition (EMT)-related proteins were significantly reduced after LHPP upregulation. Human Gene Expression Array and IPA (Ingenuity Pathway Analysis) commercial software were applied to identify differentially expressed genes (DEGs) and potential cell signaling pathways. A total of 330 different genes were observed, including 177 upregulated genes and 153 downregulated genes. Bioinformatics analysis suggested that the transforming growth factor- $\beta$ (TGF- $\beta$ ) signaling pathway was highly inactivated in this study. Then, Smad 3 phosphorylation was apparently decreased, whereas Smad7 expression was markedly enhanced after upregulating LHPP expression. These results were proven once again after TGF- $\beta 1$ stimulation. Furthermore, a specific inhibitor of Smad3 phosphorylation (SIS3) was applied to verify that LHPP repressed EMT of cancer cells by attenuating TGF- $\beta /$ Smad signaling. The results suggested that suppression of the TGF- $\beta /$ Smad signaling pathway by LHPP overexpression could be abolished by SIS3.

Cell Death Discovery (2021)7:273; https://doi.org/10.1038/s41420-021-00657-z

\section{INTRODUCTION}

Colorectal cancer (CRC) is one of the most malignant gastrointestinal cancers worldwide. Although the prognosis of patients with CRC has improved due to recent developments in colonoscopy, a 5-year relative survival still remains less than $50 \%$ in lowincome countries $[1,2]$. The situation in China has become more serious. The estimated new CRC cases and deaths of colorectal cancer in 2015 were 376,300 and 191,000, respectively [3]. The number of patients with $C R C<45$ years old was surprisingly high $(25,300)$ [3]. Thus, it is urgent to uncover the pathological mechanism of colorectal cancer to develop new therapy.

CRC development is a multistep process with different gene mutations, such as APC, TP53, RAS, and EGFR, promoting tumor proliferation, invasion, and metastasis [4-6]. In most cases, cancer metastasis and recurrence are considered as the first reasons for the high rate of mortality and poor prognosis of patients. Epithelial-tomesenchymal transition (EMT) is the most important part of cell invasion and migration and is also highly associated with drug resistance, cancer stemness, and apoptosis [7, 8]. Cells lose intracellular tight junctions and contacts and acquire mesenchymal traits after EMT. Many signaling pathways $[9,10]$ are involved in this phenomenon, including transforming growth factor- $\beta$ (TGF- $\beta$ ), Wnt/ $\beta$-catenin, Notch, and nuclear factor-B (NF-kB). Recently, increasing studies [11] have proven that phosphatidylinositol 3-kinase (PI3K)/ AKT also promoted EMT development. The activation of these signaling pathways mediates downstream crucial molecules. $\mathrm{E}$-cadherin protein downregulation and $\mathrm{N}$-cadherin protein upregulation are the most significant step during EMT. E-cadherin, an essential cell-to-cell adhesion protein, forms epithelial cell sheets and maintains cell quiescence. Conversely, increasing N-cadherin expression is normally observed in migrating neurons and mesenchymal cells. Other pivotal biomarkers, including Snail, Slug, Twist1, and Zeb1/2, could also regulate the EMT process during embryogenesis or tumorigenesis by decreasing E-cadherin protein expression or enhancing $\mathrm{N}$-cadherin protein expression directly or indirectly. Nowadays, increasing evidence suggested that exosomes, extracellular vehicles $30-150 \mathrm{~nm}$ in size, could also mediate EMT in different cancers [12-14].

Phospholysine phosphohistidine inorganic pyrophosphate phosphatase (LHPP), a type of histidine phosphatase protein, has been proven as a tumor suppressor in hepatocellular carcinoma [15] (HCC), cervical [16], pancreatic [17], bladder [18], and thyroid cancers

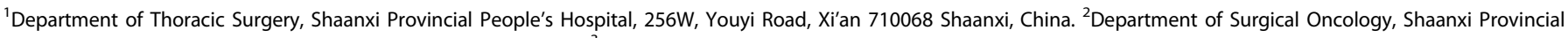

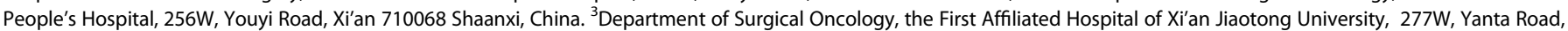
Xi'an 710061 Shaanxi, China. ${ }^{4}$ These authors contributed equally: Bin Hou, Wenhan Li. ${ }^{\circledR}$ email: dr_changdm@sina.com Edited by Erwei Sun
} 

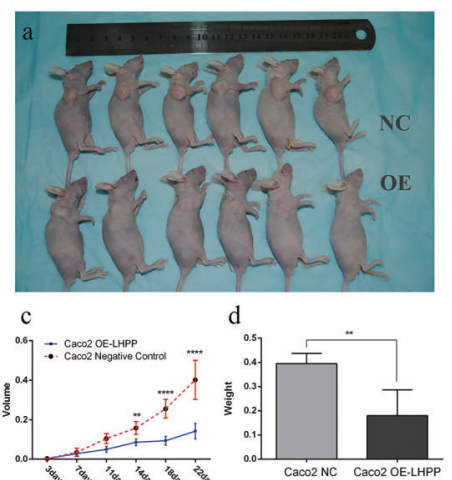

d

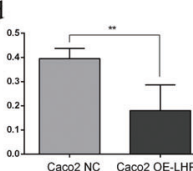$$
\text { e }
$$
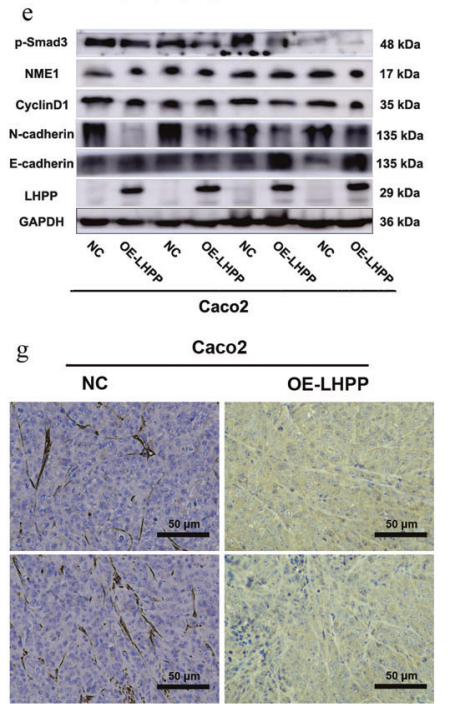

LHPP (200X)

$$
\text { i }
$$

Caco2

OE-LHPP

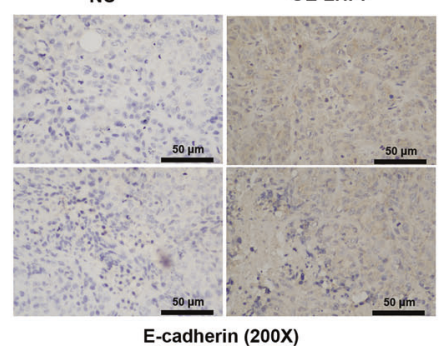

E-cadherin $(200 \mathrm{X})$
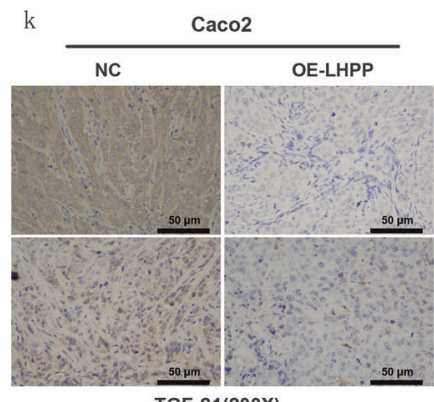

TGF- $\beta 1(200 X)$

[19] by regulating the AKT signaling pathway. In the previous research [20], LHPP protein overexpression was highly related to better prognosis and lower tumor-node-metastasis classification of patients with CRC. LHPP could inhibit colorectal cancer cell proliferation and growth by inactivating the PI3K/AKT signaling
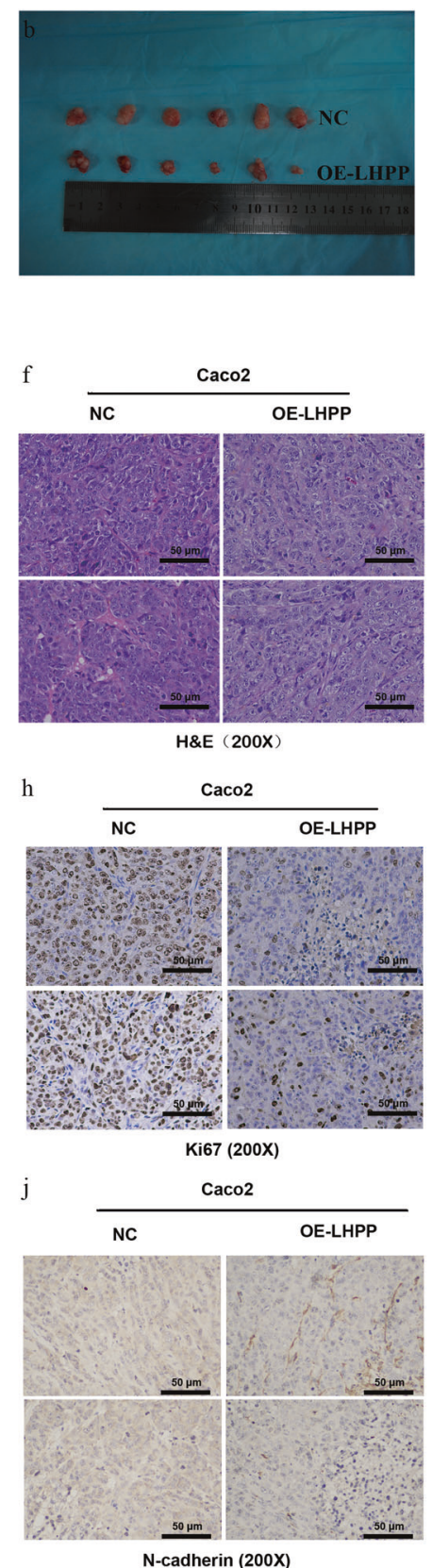

$\mathrm{N}$-cadherin $(200 \mathrm{X})$

pathway. This conclusion was consistent with previous studies. Interestingly, Tian et al. [21] predicted that miR-363-5p and miR-765 could be potential molecules to target LHPP expression in AFPnegative HCC patients, providing researchers a new perspective to investigate $L H P P$ mechanisms in tumorigenesis. 
Fig. 1 LHPP inhibits the tumor formation of colorectal cancer cells in vivo. $\mathbf{a}, \mathbf{b}$ Typical images of nude mouse model after injecting with Caco2 OE-LHPP cells and negative control cells. c, d The Graphpad Prism 6 software was used to analyze the weight and volume of tumors in different groups ( $\mathrm{g}$ in weight and $\mathrm{mm}^{3}$ in volume). The tumors in the negative group grew much larger and heavier than tumors in the OE-LHPP group. e The proteins were isolated from tumors and analyzed via western blot. Expression of EMT-related markers, such as N-cadherin, p-Smad3, were downregulated in the Caco2 OE-LHPP group. f Tumors' tissue was stained by hematoxylin and eosin (H\&E, scale bar $50 \mu \mathrm{m}, \times 200)$. $\mathbf{g}$ Expression of LHPP protein was examined by using IHC (scale bar $50 \mu \mathrm{m}, \times 200$ ). $\mathbf{h}$ The biomarker of cell viability, Ki-67, was determined by using IHC (scale bar $50 \mu \mathrm{m}, \times 200$ ). $\mathbf{i}$ Expression levels of E-cadherin in negative control and experimental groups were evaluated using $\mathrm{IHC}(\mathrm{scale}$ bar $50 \mu \mathrm{m}, \times 200)$. j The biomarker of EMT, N-cadherin protein, was tested using IHC (scale bar $50 \mu \mathrm{m}, \times 200$ ). $\mathbf{k}$ TGF- $\beta 1$ protein expression was examined by using IHC (scale bar $50 \mu \mathrm{m}, \times 200)$. ${ }^{* *} P<0.01,{ }^{* * *} P<0.001,{ }^{* * *} P<0.0001$.

This study attempted to further uncover the biological functions of LHPP protein in CRC metastasis. First, another CRC cell line (Caco2) was used to verify the conclusions of a previous study. Whether LHPP overexpression could repress CRC cell metastasis was also investigated in vivo and in vitro. Furthermore, LHPP was identified as a target gene to inhibit the TGF- $\beta$ signaling pathway by repressing Smad3 phosphorylation.

\section{RESULTS}

\section{LHPP gene definitely inhibits CRC cell growth}

To verify previous conclusions, LHPP-overexpressing LVs were transferred to Caco2 and short hair-cap LVs to Sw480, respectively. The results are shown in Supplemental Fig.1 (Sw480 LHPPoverexpression and HT-29 Sh-LHPP cell lines have been constructed before [20]). As predicted, compared to the negative group, the cell viability of the OE-LHPP group was significantly decreased $(P<0.001$; Supplemental Fig. 2a) in Caco2 cells at 3, 5, and 7 days after transfection with OE-LHPP LV. Clone numbers were also apparently reduced in the OE-LHPP group (all $P<0.001$, Supplemental Fig. $2 \mathrm{c}$, e). Conversely, downregulating LHPP protein expression could promote CRC cells proliferation. The viability of Sw480 cells was markedly higher in the Sh-LHPP group at 3, 5, and 7 days after transferring short hair-cap LVs (all $P<0.01$, shown in Supplemental Fig. 2b). Clone formation experiments also suggested that blocking LHPP expression had more clone numbers in the Sh-LHPP group $(P<$ 0.0001, Supplemental Fig. 2d, f).

To examine the influence of LHPP protein on tumor progression in vivo, Caco2 cells after transferring OE-LHPP LVs were injected into female nude mice. Each group contained six mice. Notably, tumors in the OE-LHPP group developed much slower and lighter than the NC group (all $P<0.05$, Fig. 1a-d). The mean weight of tumors in the experimental and NC groups were $0.1800 \pm 0.0435$ and $0.3950 \pm 0.0175 \mathrm{~g}$, respectively. Furthermore, tumor tissues were confirmed by using hematoxylin and eosin (H\&E) staining (Fig. 1f). The proportion of Ki-67, a specific biomarker of cell proliferation, was determined using IHC. In Fig. 1h, the Ki-67staining score was significantly higher in the NC group than in the LHPP overexpression group. Tumors and extracted total proteins were isolated to evaluate the expression of cell growth biomarkers. Consequently, cyclinD1 and NME1 expression was apparently decreased in the LHPP-overexpressing group (Fig. 1e). The expression levels of EMT-related proteins extracted from the xenograft tumor tissues via western blot analysis and IHC were evaluated. E-cadherin protein expression levels were enhanced and $\mathrm{N}$-cadherin was reduced in the Caco2 OE-LHPP group (Fig. 1e, $\mathrm{i}, \mathrm{j})$. Consistently, TGF- $\beta 1$ expression was higher in the Caco2 NC group compared to the OE-LHPP group using IHC assay (Fig. 1k).

\section{LHPP regulated CRC cell proliferation by suppressing the transition from the $G_{0} / G_{1}$ to $M$ phase}

In Supplemental Fig. 3a, b, FCM indicated that upregulating LHPP expression in $\mathrm{Caco} 2$ cells reduced the proportion of S-phase cells. Proteins that were involved in regulating the cell cycle, including p53, cyclinD1, CDK4, PCNA, and NME1, had a significantly positive difference between Caco2 NC and OE-LHPP groups (Supplemental Fig. 3e, f). LHPP impeded the expression of cyclinD1/CDK4, NME1, and PCNA expression and promoted p53 expression. In addition, LHPP silencing demonstrated a remarkable reduction in the $\mathrm{G}_{0} / \mathrm{G}_{1}$ phase and an enhancement in the S-phase (Supplemental Fig. 3c, d). CyclinD1, NME1, and PCNA expression were elevated after LHPP depletion (Supplemental Fig. 3e, f). Consistently, LHPP knockdown decreased p53 expression. These results suggested that $L H P P$ could mediate the cell cycle by downregulating cyclinD1/CDK4 expression and upregulating p53 expression.

\section{LHPP suppressed CRC migration and invasion in vitro and in vivo}

To investigate whether LHPP could influence migration and invasion abilities of CRC cells, wound-healing assay and Transwell assay with or without the Matrigel matrix layer in the chambers (50-100 $\mu$ matrix gel per well, diluted 1:8, dilution with medium). Increasing LHPP expression apparently attenuated CRC migration and invasion abilities compared to their corresponding groups (all $P<0.05$, Fig. $2 a-d)$. Consistent with the results above, LHPPdepletion increased cell numbers in the Sw480 and HT-29 Sh-LHPP groups compared to NC groups (Fig. 2e, f). There were significant differences between experimental and NC groups (all $P<0.01$, Fig. $2 \mathrm{~g}, \mathrm{~h}$ ). The results of the wound-healing assay showed the blank area in Sw480 overexpression groups was larger than the blank area in the control groups at 24 and $48 \mathrm{~h}$ (Fig. 2i). While knockdown LHPP expression promoted HT-29 cells woundhealing rate at 24 and $48 \mathrm{~h}$ (Fig. 2j). A microscope was used to observe cell shape alternation. In Fig. 2k, HT-29 cells gradually loosened intracellular tight junctions between cells after reducing LHPP expression, suggesting that HT-29 acquired more mesenchymal traits. Conversely, upregulating LHPP expression could reverse the mesenchymal features of $\mathrm{CaCO} 2$ cells and retain cell epithelial integrity.

To further determine whether LHPP affected CRC cell migration in vivo, $\mathrm{Caco} 2$ cells were injected into BALB/c-nude mice through the tail vein with stable LHPP overexpression. Lung metastatic nodules were counted under microscopy by H\&E staining (Fig. 2l, $\mathrm{m})$. The Number of metastatic nodules in OE-LHPP was lesser than in the NC group (Fig. $2 \mathrm{n}, P<0.05$ ).

\section{LHPP repressed CRC cell EMT and influenced matrix metalloproteinase (MMP) levels}

The EMT is a complex process that involves the activation of many molecules, including E-cadherin, N-cadherin, Slug, Snail, and Twist $1 / 2$. Therefore, western blot assay was used to determine the expressions of these proteins. Increasing LHPP expression evidently caused the suppression of N-cadherin, Slug, Snail, and Twist 1 in Sw480 and Caco2 cells and the significant promotion of E-cadherin (Fig. 2o, p, q, s; all $P<0.05$ ). LHPP depletion produced opposite results. E-cadherin expression was much lower in Sw480 and HT-29 Sh-LHPP cells than in their counterparts (Fig. 2o, p, r, t; all $P<0.001)$. The other key components of EMT, such as $\mathrm{N}$ cadherin, Slug, Snail, and Twist1, were highly activated in Sw480 and HT-29 cells after knockdown LHPP expression.

Generally, MMP families disrupted the basal lamina and invaded the epithelial layer up to the deep layer. Among them, MMP2 and MMP9 played a crucial role in this process. Thus, MMP2 expression was evaluated in different CRC cell lines. As expected, compared 
a

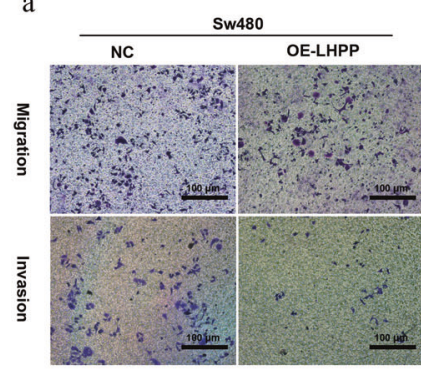

c
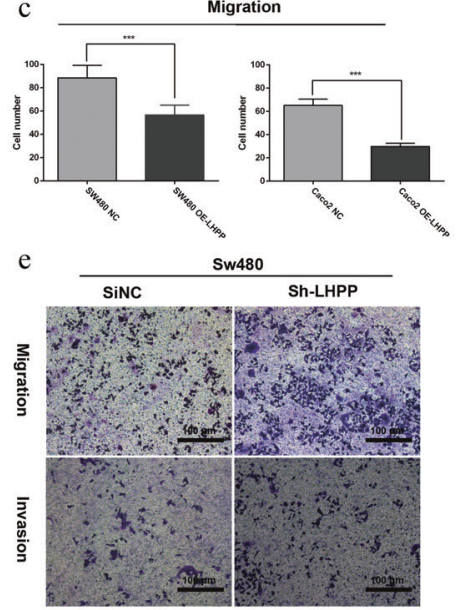

g

Migration

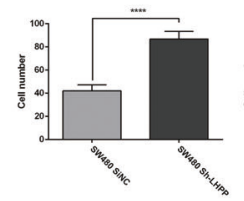

1

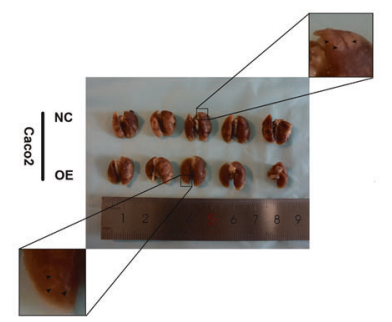

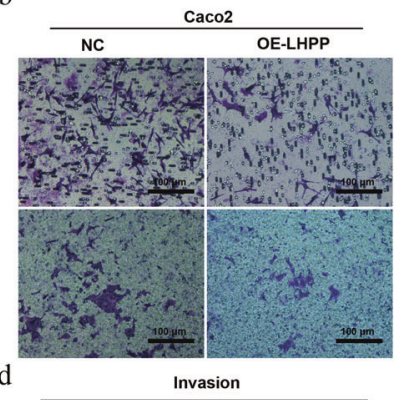
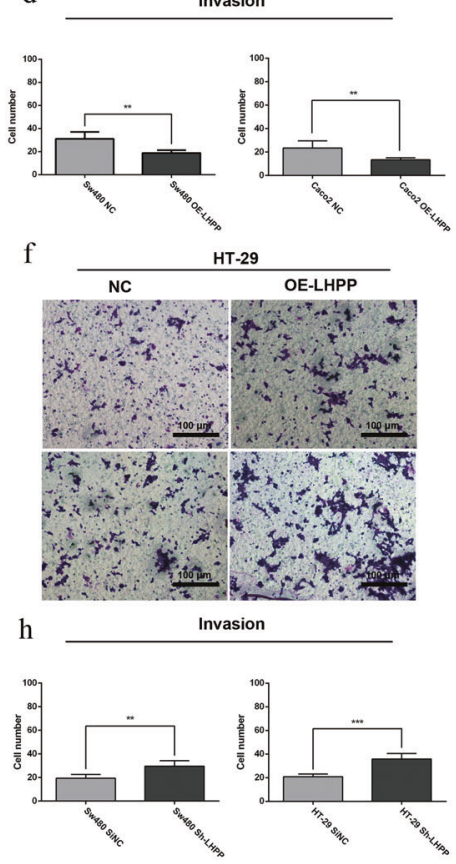

$\mathrm{m}$
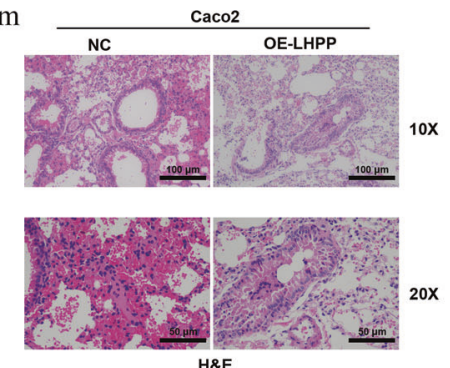

H\&E

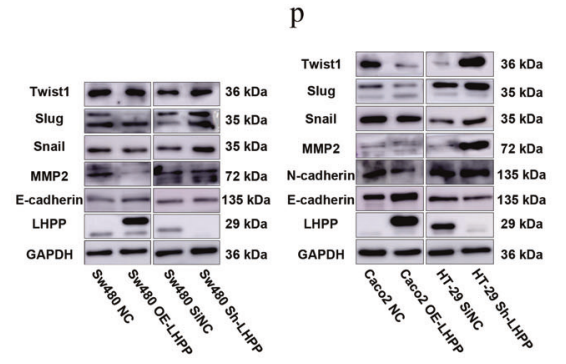

$\mathrm{q}$

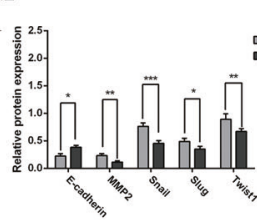

S

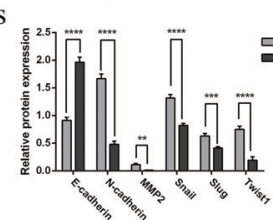

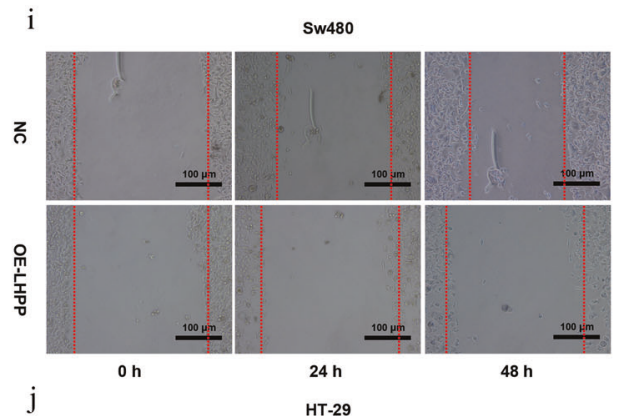

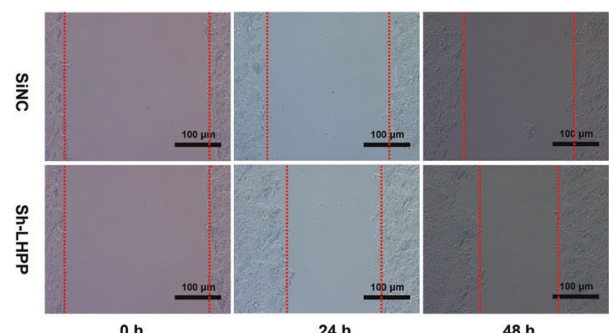

$\mathrm{oh}$

$\mathrm{k}$

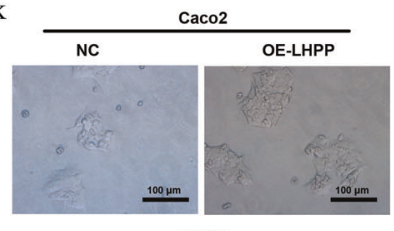

HT-29
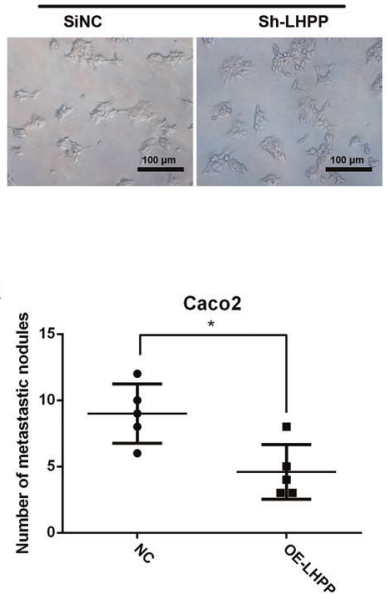

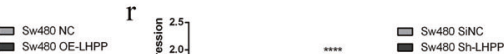

to negative groups, LHPP Overexpression positively repressed the MMP2 protein level in Sw480 and Caco2 cell lines (Fig. 2o, p, $P<$ 0.01 ). In contrast, MMP2 were upregulated in Sw480 and HT-29 LHPP-depletion groups (Fig. 2o, p, $P<0.01$ ). Accordingly, these above results revealed that $L H P P$ could negatively mediate EMTrelated proteins and suppress $C R C$ metastasis.
LHPP influenced cancer cell migration and invasion by mediating the TGF- $\beta /$ Smad signaling pathway

The mechanism of LHPP-mediated tumorigenicity was further investigated by microarray and IPA. Hierarchical clustering analysis demonstrated that LHPP overexpression led to a significant gene expression profile with 177 upregulated genes and 153 
Fig. 2 LHPP restains metastatic ability of colorectal cancer cells in vivo and vitro. Effect of LHPP overexpression on the migration and invasion (matrix gel 50-80 $\mu$, dilution 1:8, 8- $\mu \mathrm{m}$ pore) of Sw480 (a) and Caco2 (b) cell lines compared to their corresponding control groups (scale bar, $100 \mu \mathrm{m}, \times 100$ ). The quantification of migration and invasion in Sw480 cells (c) and Caco2 (d) were calculated using the Graphpad Prism 6 software according to Transwell assay, Migrated and invasive cells were stained and counted in at least five microscope fields. Blocking LHPP increased migration and invasion abilities of (matrix gel 50-80 $\mu \mathrm{l}$, dilution 1:8, 8- $\mu \mathrm{m}$ pore) Sw480 (e) and HT-29 (f) cells when compared to negative groups (scale bar, $100 \mu \mathrm{m}, \times 100)$; The statistical differences were calculated by the Graphpad Prism 6 software HT-29 (g) and Sw480 (h). Migrated and invasive cells were stained and counted in at least five microscope fields. i Effect of LHPP overexpression on the migration of Sw480 cells at 24 and $48 \mathrm{~h}$ (scale bar $100 \mu \mathrm{m}, \times 100$ ). j LHPP downregulation promoted HT-29 cells migration determined by wound-healing assay at 24 and $48 \mathrm{~h}$ (scale bar $100 \mu \mathrm{m}, \times 100$ ). $\mathbf{k}$ The change of Caco2 cells' shape following enhancement of LHPP expression; The change of HT-29 cells' shape after reduction of LHPP expression (scale bar, $100 \mu \mathrm{m}, \times 100$ ). I The representative images of lungs from nude mice $(n=5)$, black arrows showed tumor metastasis. $\mathbf{m}$ Lung nodules were identified using H\&E staining. $\mathbf{n}$ Average number of tumor nodules in lung metastasis in Caco2 OE-LHPP group and their control group. o EMT-related proteins including E-cadherin, MMP2, Snail, Slug, and Twist 1 were evaluated by using western blot in Sw480 cells after upregulating and downregulating LHPP expression. p Protein levels of Ecadherin, N-cadherin, MMP2, Snail, Slug, and Twist1 were tested using Western blot assay in Caco2 with high expression of LHPP and HT-29 with low expression of LHPP. q-t The Graphpad Prism 6 and Image J software were applied to observe the statistical differences between the experimental group and their control group. ${ }^{*} P<0.05,{ }^{* *} P<0.01,{ }^{* * *} P<0.001,{ }^{* * *} P<0.0001$.

downregulated genes (Fig. 3a, b and Table 1). IPA showed that various signaling pathways were involved in CRC development after LHPP overexpression (Fig. 3c and Table 2). Among them, the TGF- $\beta$ signaling pathway attracted the authors' attention as it was highly correlated with EMT and consistent with previous observation. The expression level of pivotal molecules in the TGF- $\beta$ signaling pathway was examined. The results showed that LHPP overexpression apparently caused a reduction of $\mathrm{p}$-Smad3 protein and a significant increase of Smad7 which was a negative regulator in the TGF- $\beta /$ Smad signaling pathway (Fig. $3 \mathrm{~d}-\mathrm{i}$, all $P$ value $<0.01)$. These conclusions were reversed after LHPP knockdown in Sw480 and HT-29 cell lines (Fig. 3d-i, all $P$ value $<0.01$ ). There was no significant difference observed in Fos and Smad4 protein expression levels between the experimental groups and NC groups.

The expression level of nuclear proteins, such as p-Smad3, Snail, Slug, Twist1, and Smad4, was also determined. LHPP suppressed Smad3 phosphorylation, leading to the obstruction of EMT-related proteins transcription (Fig. 3j-n). This finding was also proven after blocking LHPP expression (Fig. 3j-n). These data suggested that LHPP probably inhibited CRC migration and invasion by repressing Smad3 phosphorylation and upregulating Smad7 expression level.

\section{Silenced LHPP had no contribution to the apoptotic rate of CRC cells}

Based on previous references, the Eif2 signaling pathway was highly associated with cell apoptosis. Subsequently, whether knockdown of LHPP expression influenced cell apoptosis was evaluated by 7-AAD/PE staining and fluorescence-activated cell sorting analysis. In Supplemental Fig. 4a-d, there was no significant difference observed between experimental groups and their counterparts. Furthermore, the key regulators in cell apoptosis and the Eif2 signaling pathway, including Bax, caspase3, Eif2, and p-Eif2, did not change after blocking LHPP expression (Supplemental Fig. 4e, f).

\section{LHPP definitely repressed TGF- $\beta$-induced EMT and metastasis ability of cancer cells}

To further support that the TGF- $\beta$ signaling pathway was involved in the mechanism of LHPP-mediated tumorigenesis, cancer cells were treated with TGF- $\beta 1(5 \mathrm{ng} / \mathrm{ml})$, the most powerful EMT inducer, after being serum starvation for $24 \mathrm{~h}$. After TGF$\beta 1$ stimulation for $24 \mathrm{~h}$, compared to the NC group, the migration and invasion abilities of Sw480 and $\mathrm{CaCO} 2$ (Fig. 4a) with stable LHPP overexpression were also significantly impaired. Statistical results are shown in Fig. 4b, c, respectively. Conversely, silencing LHPP expression enhanced the metastatic ability of Sw480 and HT-29 cells (Fig. $4 d$ ) after TGF- $\beta 1$ stimulation for $24 \mathrm{~h}$. Statistical results were shown in Fig. $4 \mathrm{e}, \mathrm{f}$, respectively. Moreover, the wound-healing assay indicated LHPP-overexpressing Caco2 had more blank area in comparison to the corresponding group after TGF- $\beta 1$ stimulation $24 \mathrm{~h}$ (Fig. $4 \mathrm{~g}$ ). Blocking expression of LHPP in HT-29 cells led to a stronger healing ability (Fig. 4h) following TGF$\beta 1$ stimulation.

Furthermore, the IF assay was performed to determine the $\mathrm{p}$-Smad3 protein level after TGF- $\beta 1$ stimulation. Consistent with these observations, the IF signal of $\mathrm{p}$-Smad3 was obviously impaired in $\mathrm{CacO} 2$ cells with stable upregulation of LHPP (Fig. 5a). In contrast, LHPP knockdown apparently enhanced TGF- $\beta$-induced Smad3 phosphorylation in HT-29 cells (Fig. 5b). These results indicated LHPP certainly weakened TGF- $\beta$-induced CRC metastasis by mediating Samd3 phosphorylation in the TGF- $\beta$ signaling pathway.

With TGF- $\beta 1$ activation, the expression level of EMT-related markers involved in the TGF- $\beta$ signaling pathway was examined. In Fig. 5c, d, E-cadherin expression was remarkably increased in Sw480 and Caco2 cell lines with stable LHPP overexpression compared to NC groups after TGF- $\beta 1$ stimulation. Data showed an apparent reduction in the expression levels of EMT-related proteins, including N-cadherin, MMP2, Snail, Slug, and Twist1. Statistical results are shown in Fig. 5e, g. Notably, this phenomenon was reversed by downregulating LHPP expression. In response to TGF- $\beta$-induced EMT, the HT-29-Sh-LHPP and Sw480-Sh-LHPP groups demonstrated obviously higher expression levels of N-cadherin, MMP2, Snail, Slug, and Twist1 but a lower expression level of E-cadherin (Fig. 5c, d). Statistical results are shown in Fig. 5e, g. As for the crucial points involved in the TGF- $\beta / S$ mad signaling pathway, the $p-S m a d 3$ protein level was also suppressed in Sw480 and Caco2 OE-LHPP groups after TGF- $\beta 1$ activation compared to NC groups. The opposite result was observed in LHPP knockdown cells. Smad3 phosphorylation was highly activated after TGF- $\beta 1$ stimulation in HT-29 and Sw480 cell lines. This result was supported by the IF assay mentioned previously (Fig. 5a, b).

Furthermore, cell nuclear proteins, including p-Smad3, Snail, Slug, and Twist1, were also determined after TGF- $\beta 1$ stimulation for $24 \mathrm{~h}$. As expected, the expression levels of $\mathrm{p}-\mathrm{Smad} 3$, Snail, Slug, and Twist 1 were markedly decreased in Sw480 and Caco2 cells (Fig. 6). Conversely, blocking LHPP significantly promoted the expression of nuclear proteins, such as p-Smad3, Snail, Slug, and Twist1, in HT-29 and Sw480 cells compared to their counterparts.

Suppression of the TGF- $\beta$ /Smad signaling pathway by LHPP overexpression could be abolished by SIS3, a specific inhibitor of Smad3 phosphorylation, in CRC cells

The above results suggested that LHPP could impair TGF- $\beta$-mediated EMT and metastatic cell ability by inactivating the TGF- $\beta / S$ mad signaling pathway, whereas other non-Smad canonical signaling pathways, such as the mitogen-activated protein kinase (MAPK) pathway, might also be involved in TGF- $\beta$-induced EMT. To 
a

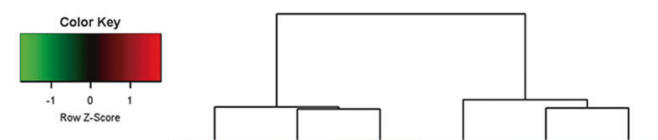

b

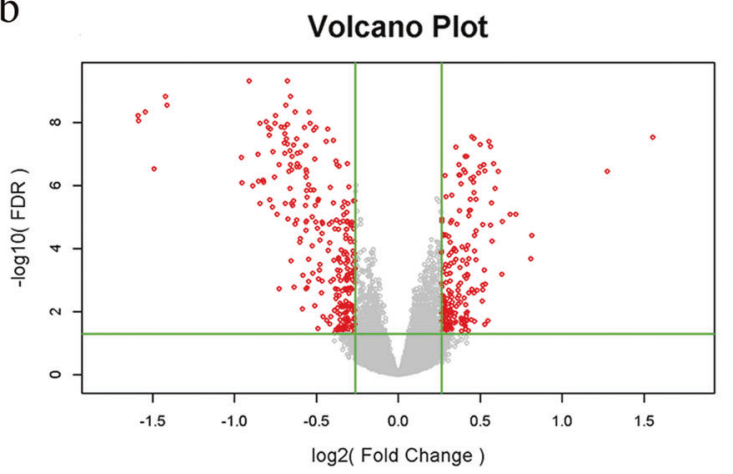

$\square$ positive z-score $\square$-score $=0 \quad \square$ negative z-score $\square$ no activity pattern available - $\square$ - Ratio

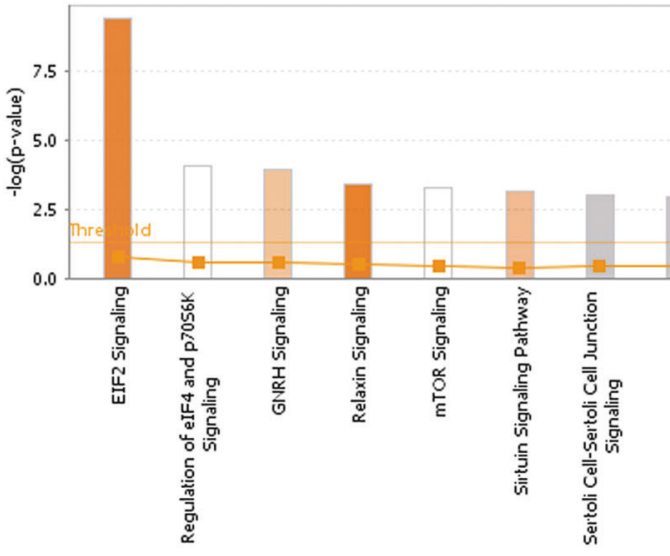

d

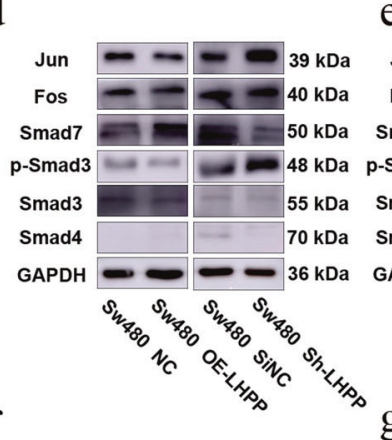

e

Jun $-=39 \mathrm{kDa}$

Fos $--240 \mathrm{kDa}$

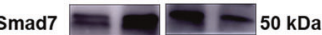

$\mathrm{d} 300-48 \mathrm{kDa}$
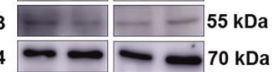

$-0-36 \mathrm{kDa}$

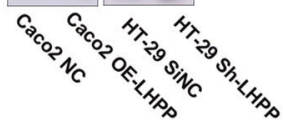

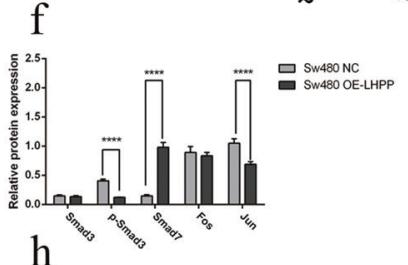

$\mathrm{h}$

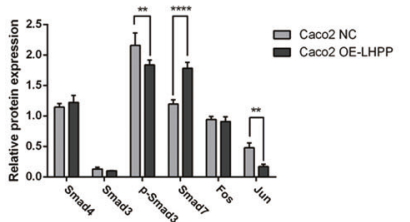

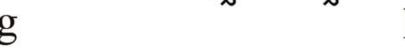

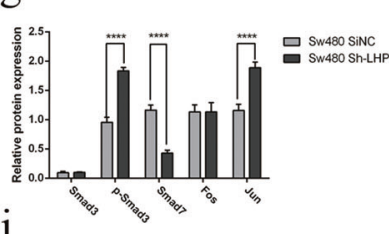

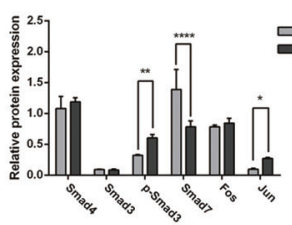

investigate the specificity of the TGF- $\beta / S$ mad pathway in CRC progression, Sw480, Caco2, and HT-29 cells were pretreated with different concentrations of SIS3 for $\sim 4-6 \mathrm{~h}$. Subsequently, TGF- $\beta 1$ $(5 \mathrm{ng} / \mathrm{ml})$ was added into the medium after serum starvation for $24 \mathrm{~h}$. In Supplemental Fig. 5, SIS3 markedly reduced the expression level of

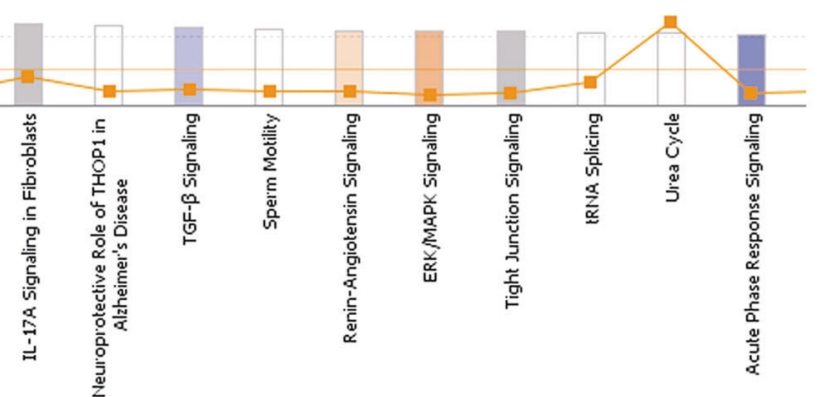

$\mathrm{j} \quad$ Nucleus Proteins

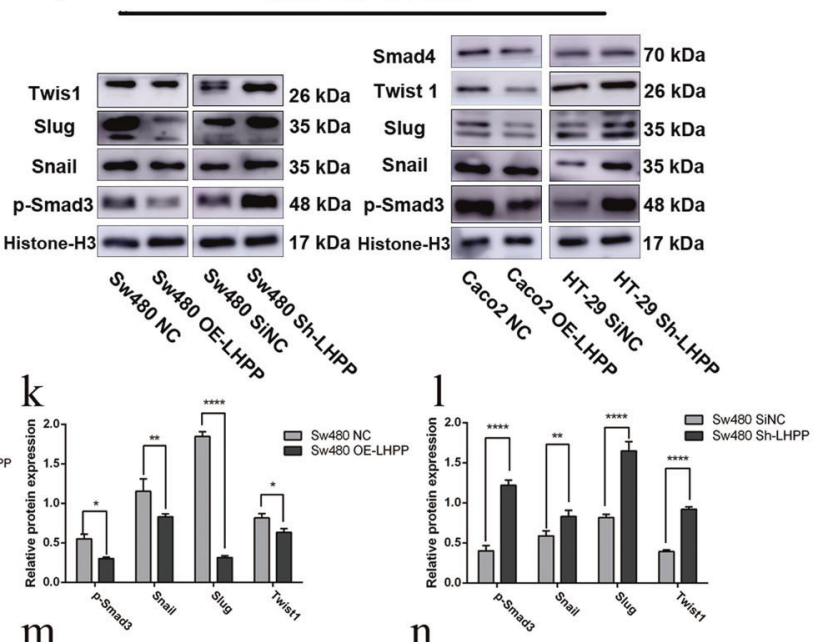

$\mathrm{m}$

n

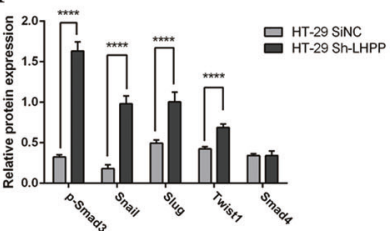

-Smad3 in Sw480 (3 ng/ml) and Caco2 $(5 \mathrm{ng} / \mathrm{ml})$ cells. Besides, HT-29 cells treated with $10 \mathrm{ng} / \mathrm{ml}$ SIS3 showed a significant decrease in expression of p-Smad3. Therefore, we chose $3 \mathrm{ng} / \mathrm{ml}, 5 \mathrm{ng} / \mathrm{ml}$, and $10 \mathrm{ng} / \mathrm{ml}$ SIS3 to block phosphorylation of Smad3 in Sw480, Caco2, and HT-29 cell lines, respectively. 
Fig. 3 Results of human microarray and Ingenuity pathway analysis (IPA), Caco2 NC groups: W2480-2482, Caco2 OE-LHPP groups: W2483-2485. a Hierarchical clustering of genes which were differentially expressed in Caco2 LHPP overexpression group and negative control group; The cut-off values were | Fold change $\mid \geq 1.2$ and FDR $<0.05$. b Volcano plot: red points mean genes with statistical difference at least 1.2 -fold change and FDR $<0.05$. $c$ Ingenuity pathway analysis. The orange rectangle means activated cell pathway and the blue rectangle means inactivated cell pathway. Positive $z$ score $>2.0$ was regarded as highly activated. Conversely, a negative $z$ score $<-2.0$ was regarded as highly inhibited; TGF- $\beta /$ Smad signaling pathway was inactivated after upregulating the expression of LHPP in the Ccaco2 cell line. Pivotal molecules of TGF- $\beta /$ Smad signaling pathway, including Smad3, p-Smad3, Smad4, Smad7, Jun, and Fos, were evaluated in Sw480 (d) and Caco2 and HT-29 cell lines (e) using western blot assay. $\mathbf{f}-\mathbf{i}$ Relative expression levels of these proteins were calculated using Image J and Graphpad Prism 6 software. j Cell nuclear proteins, such as p-Smad3, Smad4, Snail, Slug, and Twist1 were also examined using western blot, Histon-H3 was served as control. The quantification results were presented in $\mathbf{k}$ to $\mathbf{n}$. ${ }^{*} P<0.05,{ }^{* *} P<0.01,{ }^{* * *} P<0.001,{ }^{* * * *} P<0.0001$.

Table 1. A part of differentially expressed genes is shown.

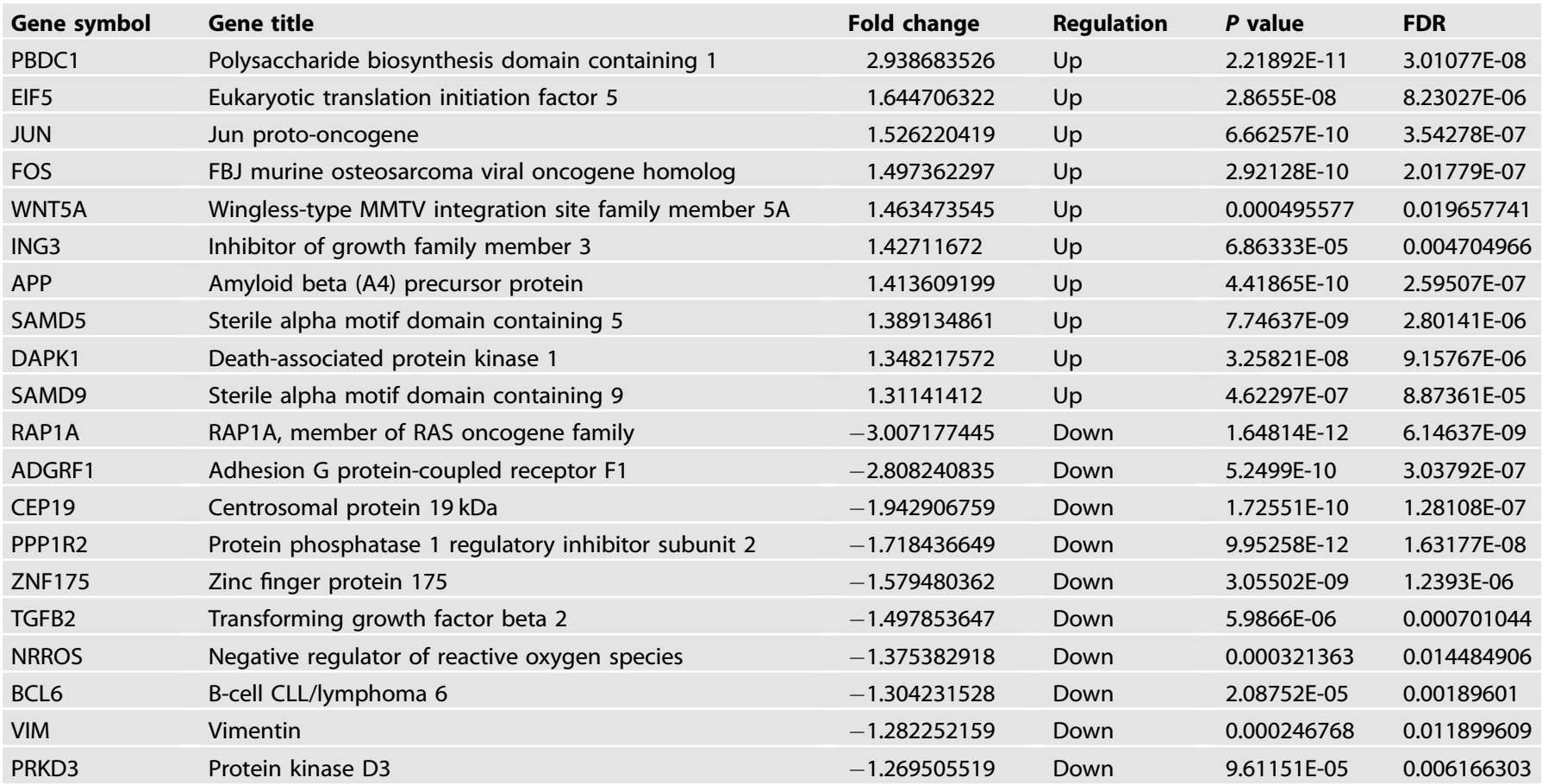

The differentially expressed genes were analyzed: Human Gene Expression Array and IPA analysis after overexpressing LHPP in Caco2 cells compared to the corresponding group. Significant difference was |fold change $\mid \geq 1.2$ and FDR $<0.05(P<0.05)$. " + " means this gene was upregulated and " - " means this gene was downregulated.

SIS3 was administered to block the TGF- $\beta /$ Smad signaling pathway in LHPP upregulation and downregulation groups. Consequently, SIS3 treatment could abolish changes of EMTrelated protein levels, such as $\mathrm{E}$-cadherin, $\mathrm{N}$-cadherin, Twist1, Snail, Slug, and MMP2, in LHPP-overexpressing Sw480 and Caco2 cells (Fig. 7e, f) compared to the NC group. These were proved not only in TGF- $\beta 1$-positive groups but also in TGF- $\beta 1$-negative groups. Statistical results are shown in Fig. $7 \mathrm{~h}$, j, respectively. Consistently, SIS3 also significantly abolished EMT-related protein variation in LHPP knockdown HT-29 and Sw480 cells treated with or without $5 \mathrm{ng} / \mathrm{ml} \mathrm{TGF- \beta 1} \mathrm{(Fig.} \mathrm{7e} \mathrm{and} \mathrm{f).} \mathrm{Statistical} \mathrm{results} \mathrm{are}$ shown in Fig. 7i, $k$, respectively. The above results were proven again by using the Transwell assay in Caco2 LHPP upregulation (Fig. 7a) and HT-29 LHPP downregulation cells (Fig. 7b) with SIS3 pretreatment. There was no significant difference between experimental and negative control groups (Fig. 7c, d). When CRC cells treated with SIS3, LHPP could not play its role in the progression of colorectal cancer. These data indicated that LHPP did repress the TGF- $\beta /$ Smad signaling pathway by inhibiting Smad3 phosphorylation.

\section{DISCUSSION}

LHPP, a $29 \mathrm{kDa}$ tumor suppressor encoded by ten chromosomes [15], is a hydrophobic, nonsecretory, and transmembrane-free protein mainly located in the cytoplasm (60.9\%). The secondary structure of LHPP protein predicted by the SOPMA database mainly contains random crimp (36.67\%) and alpha-helix (35.93\%) belonging to the NagD superfamily [22]. NetPhos3.1 and PhosphoSite Plus software demonstrate its corresponding structure including phosphorylation, acetylation, and ubiquitination sites [22]. Recently, mounting evidence has indicated that LHPP downregulation is highly associated with the poor prognosis of patients with multiple cancers. LHPP reduction promoted bladder cancer cell proliferation and growth by mediating the AKT/ p65 signaling pathway [18]. In pancreatic cancer, enhanced LHPP expression restored PTEN protein and repressed the AKT phosphorylation resulted to inhibition of $\mathrm{PaCa}$ (Pancreatic cancer) progression and metastasis [17]. Wang et al. [19] illustrated that LHPP could not only repress aggressive phenotype but also trigger autophagy in papillary thyroid cancer. In a previous study [20], LHPP expression was significantly lower in colorectal cancer tissues 
Table 2. Canonical signaling pathways are shown.

\begin{tabular}{|lll|}
\hline Ingenuity canonical pathways & $-\log (\boldsymbol{P}$ value $)$ & $\boldsymbol{z}$ score \\
\hline EIF2 signaling & 9.4 & 1.265 \\
\hline Relaxin signaling & 3.39 & 1.342 \\
\hline ERK/MAPK signaling & 2.68 & 0.707 \\
\hline BMP signaling pathway & 2.28 & 0.447 \\
\hline PPAR $\alpha /$ RXR $\alpha$ activation & 1.37 & 1.633 \\
\hline TGF- $\beta$ signaling & 2.76 & -0.447 \\
\hline Acute-phase response signaling & 2.53 & -0.816 \\
\hline SPINK1 pancreatic cancer pathway & 2.04 & -2 \\
\hline PPAR signaling & 1.91 & -0.447 \\
\hline Glioma invasiveness signaling & 1.66 & -1 \\
\hline
\end{tabular}

The canonical signaling pathways were analyzed using IPA software based on the results of differentially expressed genes. ten was the base of $-\log (P$ value). $-\log (P=0.05)=1.3$, Therefore, the statistical significance was $-\log$ ( $P$ value) $>1.3$. $z$ score $>0$ represented this signaling pathway was activated in the research; $z$ score $<0$ represented this signaling pathway was inhibited in this experiment. The more scores the signaling pathway got in the study, the more obvious the statistical difference was. The results provided us potential materials to investigate the relationship between LHPP biological functions and classical signaling pathways.

and inversely correlated to tumor severity and worse overall survival. Interestingly, LHPP dysregulation was commonly observed in many cancer types, as LHPP has common characteristics in cancer development. Thus, the biological functions of LHPP in gastrointestinal and esophageal cancers were investigated. Surprisingly, LHPP might have little impact on cell proliferation and metastasis of esophageal cancer (see results in Supplemental Fig. 6).

This research further supported the tumor-suppressor role of LHPP in CRC. Overexpressing LHPP protein not only inhibited CRC cells migration and invasion in vitro but also repressed tumor metastasis in vivo. LHPP eliminated lung metastatic nodules in nude mice. Consistently, upregulation of E-cadherin and TGF- $\beta 1$ proteins and downregulation of $\mathrm{N}$-cadherin protein were observed via IHC and western blot analysis in a xenograft model. These results were the opposite in LHPP knockdown experiments. Moreover, this study illustrated that upregulating LHPP levels inhibited EMT by mediating the classical TGF- $\beta / S m a d$ signaling pathway. Expression of the pivotal regulators in the TGF- $\beta / \mathrm{Smad}$ pathway, including p-Smad3, Smad7, and Jun, led to significant changes, such as a decrease in downstream molecules, such as Ncadherin, MMP2, Snail, Slug, and Twist1. Interestingly, we found variations of downstream molecules were more obvious after blocking LHPP expression, suggesting that LHPP might have an important role in maintaining the growth and development of normal epithelial cells. Besides, expressions of $\mathrm{N}$-cadherin and Smad4 expressions were extremely weak in the Sw480 cell line. This phenomenon might be caused by tumor heterogeneity.

Generally, TGF- $\beta$ ligand binding to TGF- $\beta$ receptors I and II transfers extracellular signal into cell nuclear components via the canonical TGF- $\beta /$ Smad pathway and non-canonical TGF- $\beta$ pathways, such as the p38/MAPK pathway, GTP pathway, PI3K/AKT pathway, and NF-KB pathway [23-25]. Therefore, SIS3, the specific inhibitor of $p$-Smad3 $[26,27]$, was used to verify the function of LHPP in the TGF- $\beta$ pathway. The changes in EMT-related protein levels were abolished in CRC cells after SIS3 treatment. Transwell assays also suggested that cell numbers in the underlayer did not significantly differ between experimental and NC groups after using SIS3. Thus, the data above uncovered the underlying mechanism of LHPP in CRC migration and invasion (Fig. 7g). The Eif2 pathway has also attracted authors' interest after bioinformatics analysis. Previously [28, 29], Eif2 phosphorylation induced
CHOP protein levels, resulting in cell apoptosis accompanied by upregulation of Bax protein level and $\mathrm{BCl}-2$ downregulation. Thus, cell apoptosis and the expression levels of $\mathrm{p}$-Eif2 and Bax proteins were evaluated after LHPP knockdown, but no statistical difference was observed.

The TGF- $\beta$ superfamily of cytokines encoded by 33 distinct genes, including TGF- $\beta$, bone morphogenetic proteins (BMPs), Nodal, inhibins, and growth and differentiation factors (GDFs), is evolutionarily conserved and involved in multiple cellular processes, such as cell proliferation, EMT, and immunosuppression $[30,31]$. There are 12 transmembrane kinase receptors subdivided into seven type I (termed activin receptor-like kinases, ALKs) and five type II receptors (TbRII, ActRII, ActRIIB, BMPRII, and AMHRII) $[25,30,31]$. The key mediators and signal transmitters of the TGF- $\beta$ signaling pathway are Smads. The eight Smad proteins are classified into three functional groups: five receptor-regulators Smad $1 / 5 / 8$ and Smad2/3, one co-Smad protein4 and two inhibitors for negative feedback Smad6/7. Interestingly, in the early process of tumorigenesis, TGF- $\beta$, serves as a tumor suppressor, arrests cell cycle, and induces apoptosis via upregulating cyclin-dependent kinase inhibitor (CKIs) and downregulating c-Myc protein [24, 30,31]. However, in the late stages of cancer, TGF- $\beta$ is one of the most powerful drivers of cells progression and metastasis through activating EMT process $[25,30,31]$. This study demonstrated LHPP could mediate CRC cell EMT by inhibiting the phosphorylation of Smad3 protein and restraining extracellular signal transduction. However, at what stage does LHPP work during tumor progression: precancerosis or advanced cancer? Thus, the next study will focus on the further mechanism of LHPP biological functions during different cancer stages.

Certainly, there are some limitations to this research. First, the upstream molecular mechanism of LHPP downregulation in CRC was not explored. Tian et al. [21] illustrated that miR-365-5p and miR-765 could target LHPP expression in AFP-negative hepatocellular carcinoma (AFP-HCC). Therefore, blocking of LHPP protein levels in CRC tissues might be correlated to miRNA or CpG hypermethylation [32]. Second, the interaction between Smad3 and LHPP proteins remains unclear. Thus, further investigation, such as co-immunoprecipitation assay, into the reciprocal relationship between LHPP and Smad3 should be performed.

In conclusion, functional studies indicated that LHPP is a tumor suppressor that inhibits CRC proliferation and metastasis in vivo and in vitro. Mechanistically, LHPP specifically inactivates Smad3 phosphorylation - the key mediator in the TGF- $\beta /$ Smad signaling pathway. These novel results provide new perspectives for CRC treatment and developing therapeutic targets.

\section{MATERIALS AND METHODS}

\section{Immunohistochemistry (IHC)}

IHC was performed as described [20] previously. Briefly, heterologous tumor tissues from nude mice were fixed in formaldehyde and embedded in paraffin. Sections were incubated with rabbit polyclonal antibodies overnight at $4{ }^{\circ} \mathrm{C}$. Two independent investigators evaluated staining blindly.

\section{Cell lines and culture conditions}

Human CRC cell lines (HT-29, Sw480, and Caco2) were purchased from the Cell Bank of the Chinese Academy of Sciences (Shanghai China). Sw480 and $\mathrm{CacO} 2$ cells were cultured in complete RPMI 1640 medium (Hyclone, USA). HT-29 cells were cultivated in complete Dulbecco's modified Eagle's medium (DMEM Hyclone, USA). The medium was supplemented with $10 \%$ fetal bovine serum (FBS Gibco) and 1\% penicillin-streptomycin mixture. Cells were maintained at $37{ }^{\circ} \mathrm{C}$ in a humidified incubator with $5 \% \mathrm{CO}_{2}$.

\section{Immunofluorescence assay (IF)}

IF assay was performed as described [20] previously. Briefly, cells $\left(1 \times 10^{4}\right)$ were seeded on slides in a 24-well plate and cultured in an incubator for 


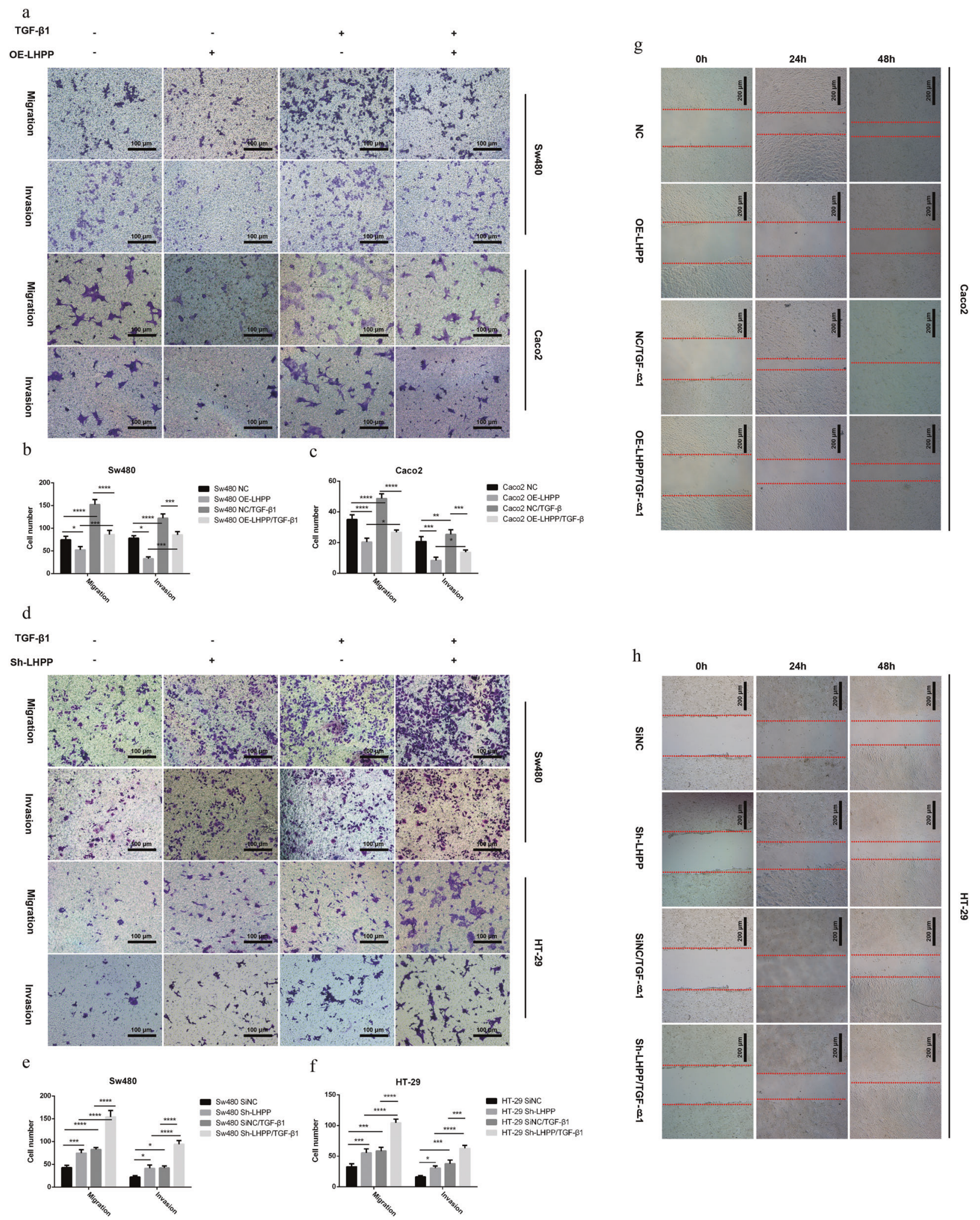

Fig. 4 The Transwell assay was performed to test migration and invasion (matrix gel $50 \mu \mathrm{\mu l}$, dilution 1:8, 8- $\mu \mathrm{m}$ pore, scale bar, 100 $\mu \mathrm{m}$, $\times 100)$ abilities of colorectal cancer cells after TGF- $\beta 1$ stimulation $(5 \mathbf{~ n g} / \mathbf{m l})$ for $\mathbf{2 4} \mathbf{~}$. a Effect of LHPP overexpression on migration and invasion abilities of Sw480 and Caco 2 cells. b, c The quantification results were calculated using the Graphpad Prism 6 software. Migration and invasion cells were stained and counted in at least five microscope fields. $\mathbf{d}$ Silencing of LHPP expression promoted TGF- $\beta 1$-induced migration and invasion abilities in Sw480 and HT-29 cells. e, f The significant difference was determined using the Graphpad Prism 6 software. Migration and invasion cells were stained and counted in at least five microscope fields. $\mathbf{g}, \mathbf{h}$ We used wound-healing assay to verify the migration capability of $\mathrm{CacO} 2$ and HT-29 cell line after treating with TGF- $\beta 1$. The scratch was observed at 0,24 , and $48 \mathrm{~h}$ using microscope (scale bar, $200 \mu \mathrm{m}, \times 40) ;{ }^{*} P<0.05,{ }^{* *} P<0.01,{ }^{* * *} P<0.001,{ }^{* * *} P<0.0001$. 

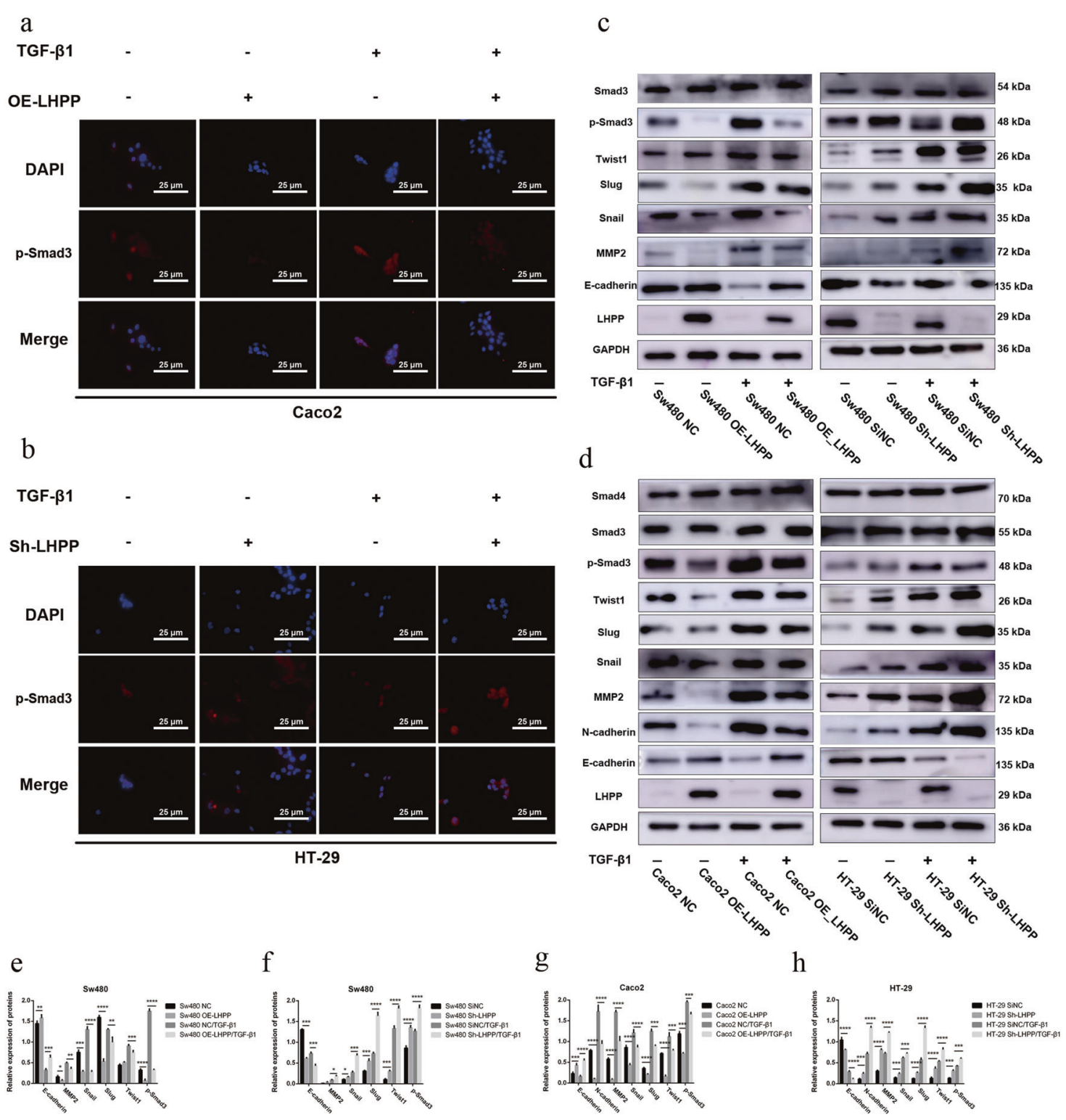

Fig. 5 LHPP blocks expression levels of key proteins in canonical TGF- $\boldsymbol{\beta} /$ Smad pathway. $\mathbf{a}$, $\mathbf{b}$ Expression level of $\mathrm{p}$-Smad3 was evaluated by using immunofluorescence assay after TGF- $\beta 1$ stimulation for $24 \mathrm{~h}$, cell nuclei were counterstained with DAPI and observed under a fluorescence microscope (scale bar: $25 \mu \mathrm{m}$ ). c, d In response to TGF- $\beta 1$ stimulation, key molecules involved in the TGF- $\beta / S m a d$ classical signaling pathway were determined using western blot assay. e, $\mathbf{f}$ Relative expression levels of these proteins were calculated using Image $J$ and Graphpad Prism 6 software. ${ }^{*} P<0.05,{ }^{* *} P<0.01,{ }^{* * *} P<0.001,{ }^{* * * *} P<0.0001$.
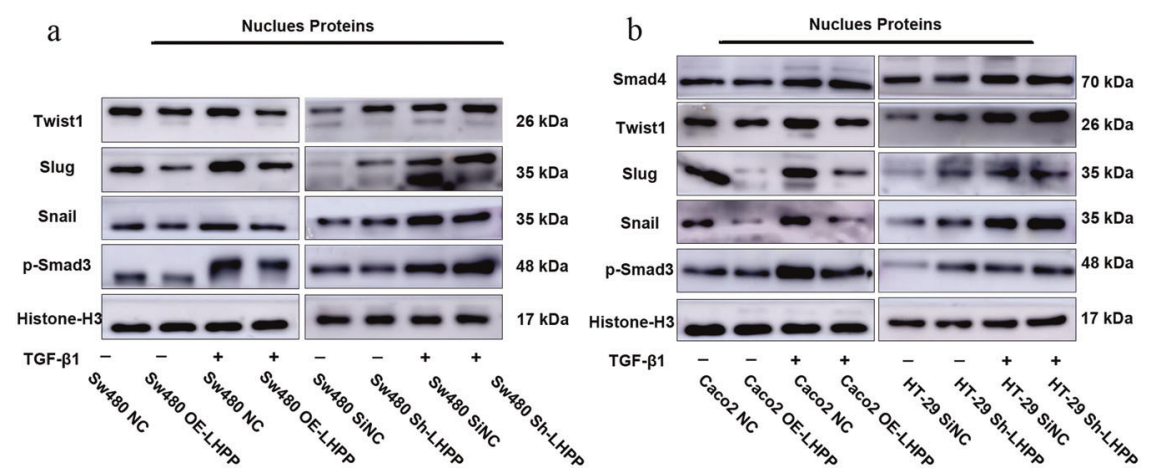

Fig. 6 We extracted nuclear proteins from different colorectal cancer cell lines after TGF- $\beta 1$ treatment for $24 \mathrm{~h}$. $\mathbf{a}$, b Expression levels of EMT-related transcription factors in colorectal cancer cells were examined by using western blot assay after changing LHPP expression. Histone-H3 protein was regarded as the control. 
a

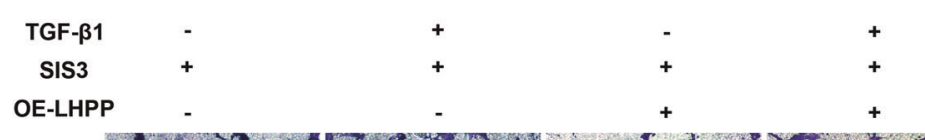

OE-LHPP
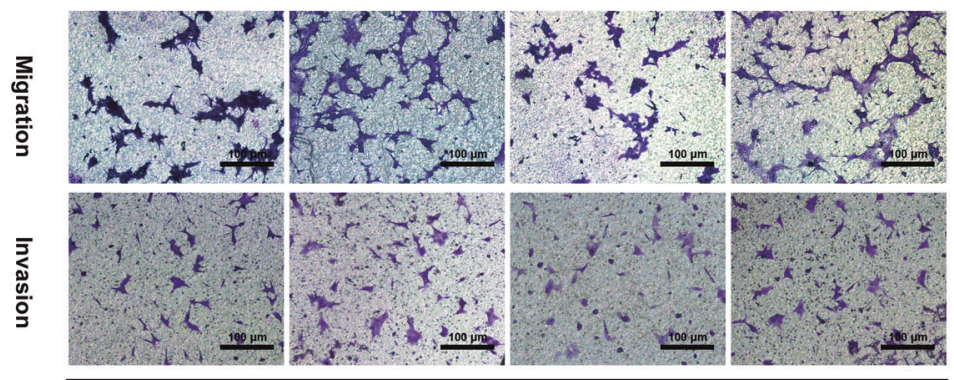

$$
\text { b }
$$

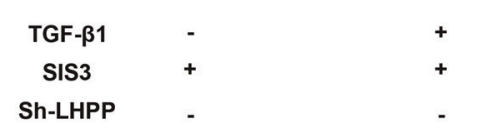

Caco2
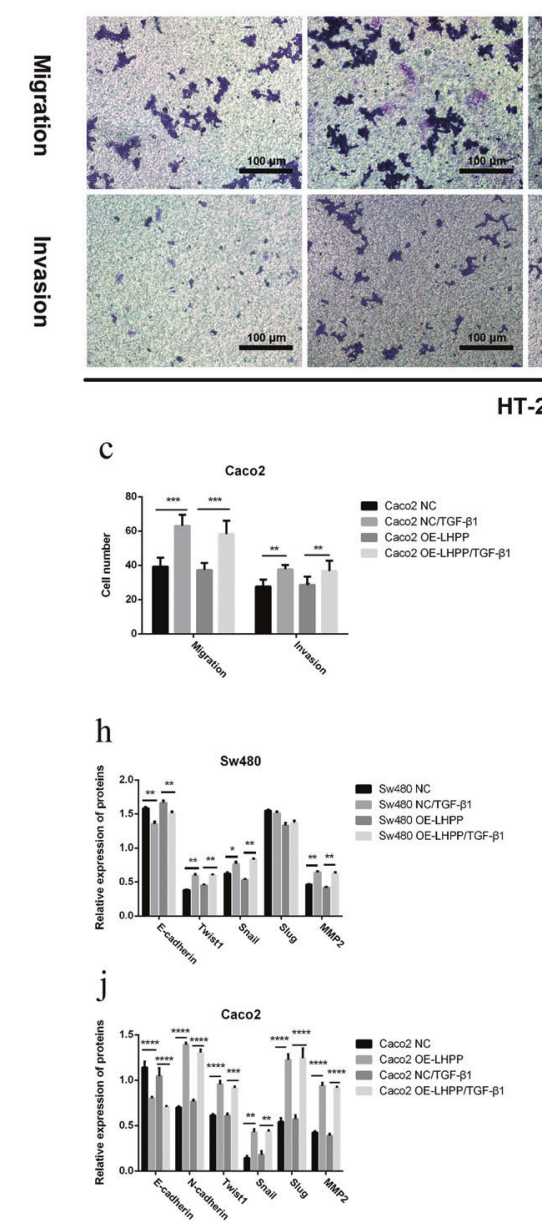

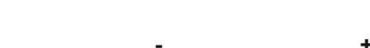

$+$

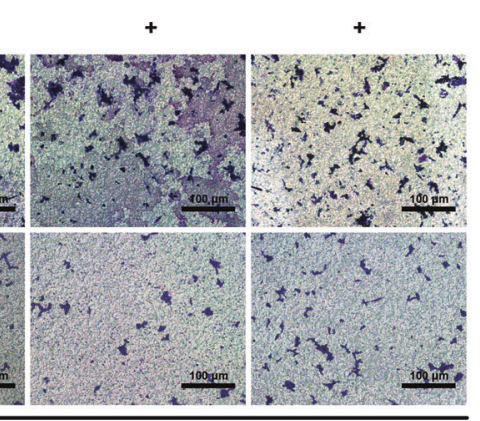

HT-29

d

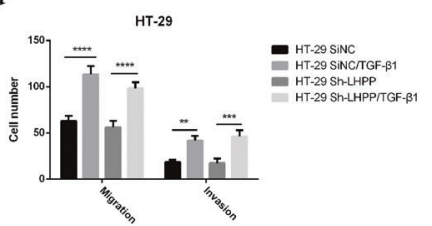

i

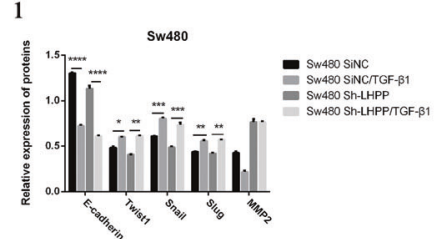

k

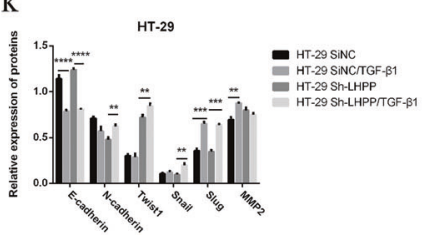

e

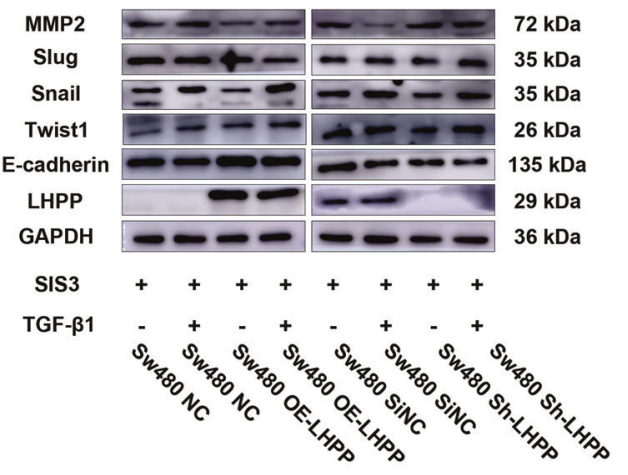

f

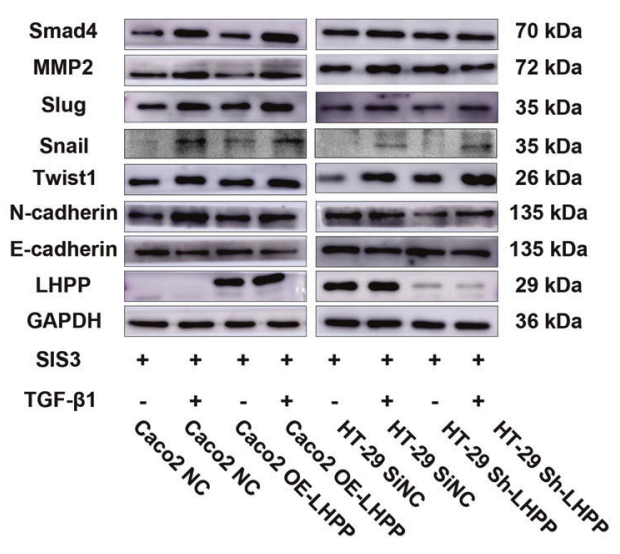

g

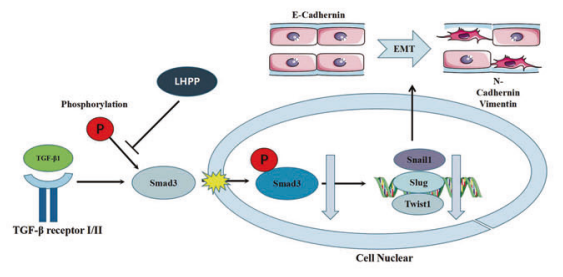

Fig. 7 In order to verify whether LHPP could inhibit migration and invasion abilities of colorectal cancer cells via inactivating phosphorylation of Smad3 specifically or not. a, b The Transwell assay was used for evaluating the influence of SIS3 (details described before) on TGF- $\beta 1$-mediated cell migration and invasion abilities (matrix gel $80 \mu \mathrm{l}$, dilution 1:8, 8- $\mu \mathrm{m}$ pore, scale bar, 100 $\mu \mathrm{m}, \times 100$ ). c, d Quantification results were determined using the Graphpad Prism 6 software. Migrated and invasive cells were stained and counted in at least five microscope fields. e, f Expression levels of EMT-related proteins in colorectal cancer cell lines. A significant difference could be observed not only in the overexpression group but also in the downexpression group with or without TGF- $\beta 1$ treatment. g Potential mechanism of LHPP in migration and invasion abilities of the colorectal cancer cell. $\mathbf{h}-\mathbf{k}$ Relative expression levels of biomarkers were calculated using Image J and Graphpad Prism 6 software. ${ }^{*} P<0.05,{ }^{* *} P<0.01,{ }^{* * *} P<0.001,{ }^{* * *} P<0.0001$. 
$24 \mathrm{~h}$. Ice-cold $4 \%$ paraformaldehyde was used to fix cancer cells for about 20 min and $0.5 \%$ Triton X-100/ phosphate buffer saline (PBS) was used to permeabilize cells for $30 \mathrm{~min}$. Cells were incubated with primary antibody (p-Smad3 dilution 1:100, Catalog no:ab52903; Abcam) overnight at $4{ }^{\circ} \mathrm{C}$ after blocking with bovine albumin (BSA) for about $20 \mathrm{~min}$. Goat anti-rabbit IgG/RBITC (Bioss, BS-0295G, Beijing, China) was added for about $1 \mathrm{~h}$. Cell nuclei were counterstained with 4,6-diamidino-2-phenylindole. Cells were observed under a fluorescence microscope.

\section{Cell transfection}

The cell transfection protocol was described before [20]. Briefly, a total of 20-30\% Sw480 and Caco2 cells were stably transfected with LHPP lentiviruses (LV) or negative control LVs (NC) according to the manufacturer's protocol (viral volume $=\mathrm{MOl} \times$ cell numbers/viral titers; GeneChem Co., Ltd, Shanghai, China; $\mathrm{MOI}=20$, cell numbers: $1-5 \times 10^{5}$, viral titers: $4 \times$ $10^{8}$ ). Lentiviral vectors used the GV208 system combined with the cytomegalovirus promoter-driven puromycin gene and green fluorescent protein. The GV248 RNA interference (RNAi) system (GeneChem, Shanghai, China) was used to impede LHPP expression. The target sequence of $L H P P$ was 5'- GAGCAAGGCCUGCGACCAUTTAUGGUCGCAGGCCUUGCUCTT-3'. The negative sequence was 5'- UUCUCCGAACGUGUCACGUTT-3'. HT-29 and Sw480 cell lines were stably transfected with LHPP-RNAi lentiviruses (viral volume $=$ MOI $\times$ cell numbers/viral titers; $\mathrm{MOI}=20$, cell numbers: $1-5 \times 10^{5}$, viral titers: $2 \times 10^{9}$ ).

\section{Nuclear protein extraction}

The Nuclear Protein Extraction kit (Abcam, USA, ab113474) was used to extract nuclear proteins from cells. Cells were cultured to $60-70 \%$ confluence, and we scraped cells into a $15-\mathrm{ml}$ conical tube after adding $1 \mathrm{ml}$ fresh PBS per $20 \mathrm{~cm}^{2}$ area. Cells were centrifuged for $5 \mathrm{~min}$ at $1000 \mathrm{rpm}$, and the supernatant was discarded. Next, cells were resuspended in $100 \mu \mathrm{l}$ of $1 \times$ preextraction buffer per $10^{6}$ cells and incubated on ice for $10 \mathrm{~min}$. The prepared extract was centrifuged for about $1 \mathrm{~min}$ at $12,000 \mathrm{rpm}$ after vigorous vortexing. Notably, it is extremely important to remove the cytoplasmic extract from the nuclear preparation. Then, two volumes of extraction buffer containing PMSF were added to the nuclear pellet (about $10 \mu \mathrm{l}$ per $10^{6}$ cells) and incubated for $15 \mathrm{~min}$ with vortexing (5-15 s) every $3 \mathrm{~min}$ for about $0.5 \mathrm{~h}$. Finally, the suspension was centrifuged again for $10 \mathrm{~min}$ at $12,000 \mathrm{rpm}$ at $4^{\circ} \mathrm{C}$ and the supernatant was transferred into a new tube. Protein concentrations were determined by using a BCA Protein Assay kit (cat. no. PA115-01; Tiangen Biotech Co. Ltd.).

\section{Western blot analysis}

The western blot was performed as described [20] previously. Total proteins were isolated from cells or tissues by using radioimmunoprecipitation assay buffer with protease inhibitors. Equal amounts of protein $(20-30 \mu \mathrm{g})$ were separated by $10 \%$ or $12 \%$ sodium dodecyl sulfatepolyacrylamide gel electrophoresis and then transferred to polyvinylidene difluoride membranes. Membranes were incubated with primary antibodies overnight at $4{ }^{\circ} \mathrm{C}$ after blocking with $5 \%$ milk, followed by incubation with a secondary antibody (1:5000). Image J software (National Institutes of Health) was used to examine the gray values of each primary antibody and glyceraldehyde 3-phosphate dehydrogenase (GAPDH). The ratio of gray values (primary antibody/GAPDH) was calculated using GraphPad Prism 6 software (Graph Pad Software, Inc.). The other antibodies are shown in the Supplemental Table.

\section{RNA extraction, reverse transcription, and real-time PCR (RT-} PCR)

The total RNA was extracted from cells using the Fastagen200 Kit (Shanghai China, Cat:220010) according to the manufacturer's protocol. CDNAs were synthesized with PrimeScript ${ }^{\mathrm{TM}}$ RT Master Mix (Takara Biotechnology, China). Quantitative RT-PCR procedures were performed by using the SYBR Green PCR Kit (Takara Biotechnology, China) in three independent experiments. The LHPP expression was calculated using the $2^{-\triangle \Delta C q}$ method. The housekeeping gene was GAPDH. The following primers and procedures were described before [20].

\section{Cell viability assay}

Cells were seeded (2000-3000 per well) in a 96-well plate and cultured for 7 days. Next, a $10 \mu$ l CCK-8 solution (E1CK-000208, Nanjing, China) was added to each well, and cells were incubated for $2 \mathrm{~h}$ under aseptic conditions in a $5 \% \mathrm{CO}_{2}$ incubator at $37{ }^{\circ} \mathrm{C}$. The spectrophotometric value of each sample was measured at $450 \mathrm{~nm}$.

\section{Colony-formation analysis}

Cells were (1000-2000 per well) plated in culture plates for 3-4 weeks at $37^{\circ} \mathrm{C}$ in a humidified environment with $5 \% \mathrm{CO}_{2}$ and stained with crystal violet staining solution(1\%) for $30 \mathrm{~min}$. The stained colonies were imaged using a camera and counted using a microscope.

\section{Cell cycle analysis}

Cells $\left(1-2 \times 10^{5}\right)$ were seeded in 6-well plates and cultured for $24 \mathrm{~h}$. Cells were digested and collected in a new EP tube and fixed them with cold ethanol at $4{ }^{\circ} \mathrm{C}$ overnight. After this, $500 \mu \mathrm{l}$ propidium iodide (PI) and RNase A (1:9) were applied to incubate cells in the darkness (Cat. no. KGA512, KeyGen Biotech, Nanjing China). The results were analyzed by using a FACSCalibur flow cytometer (BD Bioscience). The percentage of different cell cycles was calculated using Graphpad Prism 6 software (GraphPad Software, Inc.).

\section{Cell apoptosis assay}

Cells $\left(5-10 \times 10^{4}\right)$ were plated in six-well plates to culture $24-48 \mathrm{~h}$ after transfection with LVs. Cells were digested using $0.25 \%$ trypsin without EDTA and collected cells into new 15-ml tubes. Subsequently, cells were stained with $7 A A D$ for cell nucleus and $P E$ for cytomembrane (Cat. no. KGA1017, KeyGen Biotech, Nanjing China). Cell apoptosis was examined using FACSCalibur flow cytometer (BD Bioscience).

\section{Wound-healing assay}

Cells $\left(1 \times 10^{5}\right)$ were seeded in six-well plates and cultured to $>95 \%$ confluence. Wounds were scratched using a $10-\mu l$ plastic pipette tip. After PBS wash, cells were cultured with $1-2 \%$ serum. Wounded areas were photographed by phase-contrast microscopy at $0 \mathrm{~h}, 24,48 \mathrm{~h}$, respectively.

\section{Cell migration assay}

Cells $\left(2 \times 10^{4}\right)$ were seeded with serum-free medium $(200 \mu l)$ in a Transwell migration chamber (Corning, USA) with an 8- $\mu$ m pore membrane on the bottom. The chamber was inserted in a well of a 24-well plate containing $10 \%$ FBS media $\left(500 \mu \mathrm{l}\right.$ DMEM or RPMI 1640). Cells were incubated at $37^{\circ} \mathrm{C}$ in a humidified environment with $5 \% \mathrm{CO}_{2}$ for $12-24 \mathrm{~h}$, and then stained with crystal violet and detected under a microscope after being fixing with $4 \%$ paraformaldehyde. A microscope was used to image migrating cells and cell numbers were counted under five independent visual fields. Statistical analysis was done using Graphpad Prism 6 Software (GraphPad Software, Inc.).

\section{Cell invasion assay}

Transwell invasion cells $\left(1 \times 10^{5}\right)$ were plated on top of a 24-well Corning 8$\mu \mathrm{m}$ pore membrane with a serum-free medium. The matrix gel was added on top of the Transwell chamber (BD, USA, dilution 1:8, 50-80 $\mu$, diluted with medium). After 24-48 h, invading cells were washed with PBS, fixed with $4 \%$ paraformaldehyde, and stained with crystal violet. Bright-field microscopy was used to count invading cell numbers. A microscope was used to image migrating cells, and cell numbers were counted under five independent visual fields. Statistical analysis was calculated using Graphpad Prism 6 Software (GraphPad Software, Inc.).

\section{Microarray analysis}

Total RNA was isolated from Caco2 CRC cells after transfection with $O E-$ LHPP LVs and the NC group for $72 \mathrm{~h}$ (three replicates each group). RNA samples were analyzed by microarray expression profiling using the Affymetrix Human Gene 1.0 ST platform (Affymetrix) according to the manufacturer's instructions (GeneChem, Shanghai, China). Genes with $\geq 1$.2-fold change between two groups were identified as differentially expressed genes (DEGs). DEGs were analyzed using Ingenuity Pathway Analysis (IPA) commercial software

\section{Inhibitor of the TGF- $\beta$ /Smad signaling pathway}

To determine whether LHPP mediated the EMT process via the TGF- $\beta$ signaling pathway. Experimental and negative control cells were treated with TGF- $\beta 1$ (Abcam, ab50036, $5 \mathrm{ng} / \mathrm{ml}$ ) after being serum starvation for $24 \mathrm{~h}$. TGF- $\beta 1$ was reconstituted in $10 \mathrm{mM}$ citric acid $(50 \mu \mathrm{g} / \mathrm{ml})$ for storage and further diluted in PBS $(5 \mathrm{ng} / \mathrm{ml})$. Subsequently, migration 
and invasion abilities were determined using Transwell and woundhealing assays. Next, the TGF- $\beta /$ Smad inhibitor-SIS3-(MCE, USA, HY13013) was added to cancer cells. Cell migration and invasion experiments were performed once again after cancer cells were treated with SIS3. Western blot analysis was performed to evaluate the expression of total and nuclear proteins.

\section{Xenograft assays and lung metastasis models}

All animal experiments were performed in accordance with the institutional guidelines and were approved by the Laboratory Animal Center of Xi'an Jiaotong University. Four-week-old female BALB/c-nude mice were purchased from Xian Jiaotong University Animal laboratory for subcutaneous xenograft experiments. Caco 2 cells $\left(2-4 \times 10^{6} / 200 \mu \mathrm{l}\right)$ with $L H P P$-overexpression LVs and blank vectors were injected subcutaneously into mice (six mice per group). Tumor size was measured using caliper every 3 days and calculated using the formula: volume $=$ length $\times\left(\right.$ width $\left.^{2}\right) / 2$. Lung metastasis models were built by injecting Caco2 cells $\left(1-2 \times 10^{6} / 200 \mu \mathrm{l}\right)$ into tail veins (5 mice per group). After 7-8 weeks, mice were killed by cervical dislocation. Humane endpoints $[33,34]$ were as followed (i) tumor ulceration showed no stabilization within 7 days of treatment; (ii) ulcerated tumor was actively bleeding; (iii) ulcerated tumor showed visible signs of infection; (iv) animals showed discomfort associated with tumor ulceration such as biting/scratching; and (v) tumor size did not exceed $20 \mathrm{~mm}(2.0 \mathrm{~cm})$ in mice (IACUC Guideline: Tumor Induction in mice and rats). Tumors and lungs were isolated from mice. Tumor tissues were fixed in $4 \%$ paraformaldehyde and cut into $10-\mu \mathrm{m}$ sections for $\mathrm{IHC}$ analysis.

\section{Statistical analysis}

All statistical data were calculated using GraphPad Prism 6 software. The experimental results were repeated three times and expressed as the mean \pm standard error. A two-tailed Student's $t$ test was used to analyze the statistical significance between different groups. One- or twoway analysis of variance (ANOVA) followed by Bonferroni's multiple comparison test, was performed to test the difference between multiple groups. $P<0.05$ was regarded as statistically significant.

\section{DATA AVAILABILITY}

The data that support the findings of this study are available from the corresponding author upon reasonable request.

\section{REFERENCES}

1. Brenner H, Kloor M, Pox CP. Colorectal cancer. Lancet. 2014;383:1490-502.

2. Siegel RL, Miller KD, Jemal A. Cancer statistics, 2019. CA Cancer J Clin. 2019;69:7-34.

3. Chen W, Zheng R, Baade PD, Zhang S, Zeng $H$, Bray $F$, et al. Cancer statistics in China, 2015. CA Cancer J Clin. 2016;66:115-32.

4. Laurent-Puig P, Agostini J, Maley K. [Colorectal oncogenesis]. Bull Cancer. 2010;97:1311-21.

5. Hampel H, Peltomaki P. Hereditary colorectal cancer: risk assessment and management. Clin Genet. 2000;58:89-97.

6. Harrison S, Benziger $\mathrm{H}$. The molecular biology of colorectal carcinoma and its implications: a review. Surgeon. 2011;9:200-10.

7. Hanahan D, Weinberg RA. Hallmarks of cancer: the next generation. Cell. 2011;144:646-74.

8. Hanahan D, Weinberg RA. The hallmarks of cancer. Cell. 2000;100:57-70.

9. Cao J, Wu Z, Tong T, Zhu Q, Zhao E, Cui H. Advances in mesenchymal to epithelial transition factor signaling pathway and inhibitors. Sheng Wu Gong Cheng Xue Bao. 2018;34:334-51.

10. Micalizzi DS, Farabaugh SM, Ford HL. Epithelial-mesenchymal transition in cancer: parallels between normal development and tumor progression. J Mammary Gland Biol Neoplasia. 2010;15:117-34.

11. Xu W, Yang $Z$, Lu N. A new role for the PI3K/Akt signaling pathway in the epithelial-mesenchymal transition. Cell Adh Migr. 2015;9:317-24.

12. Fu X, Liu M, Qu S, Ma J, Zhang Y, Shi T, et al. Exosomal microRNA-32-5p induces multidrug resistance in hepatocellular carcinoma via the PI3K/Akt pathway. J Exp Clin Cancer Res. 2018;37:52.

13. Min $H$, Sun $X$, Yang $X$, Zhu $H$, Liu J, Wang $Y$, et al. Exosomes derived from irradiated esophageal carcinoma-infiltrating $\mathrm{T}$ cells promote metastasis by inducing the epithelial-mesenchymal transition in esophageal cancer cells. Pathol Oncol Res. 2018;24:11-18.
14. Rahman MA, Barger JF, Lovat F, Gao M, Otterson GA, Nana-Sinkam P. Lung cancer exosomes as drivers of epithelial mesenchymal transition. Oncotarget. 2016;7:54852-66.

15. Hindupur SK, Colombi M, Fuhs SR, Matter MS, Guri Y, Adam K, et al. The protein histidine phosphatase LHPP is a tumour suppressor. Nature. 2018;555:678-82.

16. Zheng J, Dai X, Chen H, Fang C, Chen J, Sun L. Down-regulation of LHPP in cervical cancer influences cell proliferation, metastasis and apoptosis by modulating AKT. Biochem Biophys Res Commun. 2018;503:1108-14.

17. Wu F, Chen Y, Zhu J. LHPP suppresses proliferation, migration, and invasion and promotes apoptosis in pancreatic cancer. Biosci Rep. 2020;40:BSR20194142.

18. Li Y, Zhang X, Zhou X, Zhang X. LHPP suppresses bladder cancer cell proliferation and growth via inactivating AKT/p65 signaling pathway. Biosci Rep. 2019;39:1-11.

19. Sun W, Qian K, Guo K, Chen L, Xiang J, Li D, et al. LHPP inhibits cell growth and migration and triggers autophagy in papillary thyroid cancer by regulating the AKT/AMPK/mTOR signaling pathway. Acta Biochim Biophys Sin. 2020;52:382-9.

20. Hou B, Li W, Li J, Ma J, Xia P, Liu Z, et al. Tumor suppressor LHPP regulates the proliferation of colorectal cancer cells via the PI3K/AKT pathway. Oncol Rep. 2020;43:536-48.

21. Tian $Z$, Yu T, Wei H, Ning N. Clinical value of LHPP-associated microRNAs combined with protein induced by vitamin $\mathrm{K}$ deficiency or antagonist-II in the diagnosis of alpha-fetoprotein-negative hepatocellular carcinoma. J Clin Lab Anal. 2020;34:e23071.

22. Chen $D, X i e P, C$ ao JW. Bioinformatics prediction and expression analysis of tumor suppressor LHPP in hepatocellular carcinoma. Med J Wuhan Univ. 2019;40:756-61.

23. Patil AS, Sable RB, Kothari RM. An update on transforming growth factor-beta (TGF-beta): sources, types, functions and clinical applicability for cartilage/bone healing. J Cell Physiol. 2011;226:3094-103.

24. Scandura JM, Boccuni P, Massague J, Nimer SD. Transforming growth factor betainduced cell cycle arrest of human hematopoietic cells requires p57KIP2 upregulation. Proc Natl Acad Sci USA. 2004;101:15231-6.

25. Cheng N, Chytil A, Shyr Y, Joly A, Moses HL. Transforming growth factor-beta signaling-deficient fibroblasts enhance hepatocyte growth factor signaling in mammary carcinoma cells to promote scattering and invasion. Mol Cancer Res. 2008;6:1521-33.

26. Shou J, Cao J, Zhang S, Sun R, Zhao M, Chen K, et al. SIS3, a specific inhibitor of smad3, attenuates bleomycin-induced pulmonary fibrosis in mice. Biochem Biophys Res Commun. 2018;503:757-62.

27. Yang $\mathrm{H}$, Zhan L, Yang T, Wang L, Li C, Zhao J, et al. Ski prevents TGF-beta-induced EMT and cell invasion by repressing SMAD-dependent signaling in non-small cell lung cancer. Oncol Rep. 2015;34:87-94.

28. Prola A, Pires DSJ, Guilbert A, Lecru L, Piquereau J, Ribeiro M, et al. SIRT1 protects the heart from ER stress-induced cell death through elF2alpha deacetylation. Cell Death Differ. 2017;24:343-56.

29. Jeon SJ, Ahn JH, Halder D, Cho HS, Lim JH, Jun SY, et al. TIPRL potentiates survival of lung cancer by inducing autophagy through the elF2alpha-ATF4 pathway. Cell Death Dis. 2019;10:959.

30. Yu Y, Feng XH. TGF-beta signaling in cell fate control and cancer. Curr Opin Cell Biol. 2019;61:56-63.

31. Akhurst RJ, Hata A. Targeting the TGFbeta signalling pathway in disease. Nat Rev Drug Discov. 2012;11:790-811.

32. Manjegowda MC, Gupta PS, Limaye AM. Hyper-methylation of the upstream CpG island shore is a likely mechanism of GPER1 silencing in breast cancer cells. Gene. 2017;614:65-73.

33. Workman P, Aboagye EO, Balkwill F, Balmain A, Bruder G, Chaplin DJ, et al. Guidelines for the welfare and use of animals in cancer research. $\mathrm{Br} J$ Cancer. 2010;102:1555-77.

34. Wallace J. Humane endpoints and cancer research. ILAR J. 2000;41:87-93.

\section{ACKNOWLEDGEMENTS}

This research was supported by a grant from the Science and Technology Foundation of Shaanxi Province (S2018-YFZDSF-0102).

\section{AUTHOR CONTRIBUTIONS}

$\mathrm{DMC}, \mathrm{BH}$, and WKL designed the research. $\mathrm{BH}, \mathrm{FYZ}, \mathrm{ZL}$, and SLW performed the experiments. $\mathrm{BH}, \mathrm{PX}, \mathrm{QNZ}$, and SLW contributed to the analysis and acquisition of the data. $\mathrm{BH}$ and FYZ wrote the manuscript. DMC, PX, and FYZ revised and edited the manuscript and revised it critically for important intellectual content. DMC provided funding support. All authors read and approved the manuscript.

\section{COMPETING INTERESTS}

The authors declare no competing interests. 
14

\section{ETHICS STATEMENT}

All animal experiments were performed in accordance with the protocol and guidelines and approved by the Laboratory Animal Center of Xi'an Jiaotong University.

\section{ADDITIONAL INFORMATION}

Supplementary information The online version contains supplementary material available at https://doi.org/10.1038/s41420-021-00657-z.

Correspondence and requests for materials should be addressed to Dongmin Chang.

Reprints and permission information is available at http://www.nature.com/reprints

Publisher's note Springer Nature remains neutral with regard to jurisdictional claims in published maps and institutional affiliations.
Open Access This article is licensed under a Creative Commons Attribution 4.0 International License, which permits use, sharing, adaptation, distribution and reproduction in any medium or format, as long as you give appropriate credit to the original author(s) and the source, provide a link to the Creative Commons license, and indicate if changes were made. The images or other third party material in this article are included in the article's Creative Commons license, unless indicated otherwise in a credit line to the material. If material is not included in the article's Creative Commons license and your intended use is not permitted by statutory regulation or exceeds the permitted use, you will need to obtain permission directly from the copyright holder. To view a copy of this license, visit http://creativecommons. org/licenses/by/4.0/.

(c) The Author(s) 2021 